\title{
ESTRUTURA, ESTRATIGRAFIA E EVOLUÇÃO DAS BACIAS MARGINAIS BRASILEIRAS
}

\author{
HILDEBERTO A. OJEDA Y OJEDA*
}

\begin{abstract}
The structural framework of the Brazilian marginal basing is basically defined by the following features: synthetic and antithetic tilted step-fault blocks, structural inversion zones, hinges with compensation grabens, shallow platforms, homoclinal structures, growth faults with rollovers, salt and shale diapirs, and igneous structures. The two tilted step-fault blocks are interpreted as complementary synchronous systems, separated by the inversion zone. They developed in the Early Cretaceous (Neocomian-Barremian) in rift valleys adjacent to a central graben and related to the rift phase of the Gondwana continent. The hinges, shallow platforms, homoclinal structures and diapirs were preferentially formed in the Late Cretaceous-Recent, during the transitional and drift phases of the South American and African plates.

Two Aptian evaporitic cycles: Paripueira and Ibura were distinguish in the Sergipe-Alagoas type-basin, and tentatively correlated with the counter parts of the other Brasilian marginal basins. Based on paleogeographic, paleoenvironmental, tectonic-sedimentary, lithological, paleoontological and geochemical considerations, the following points are admitted: a) the evaporitic basins were controlled by assymmetric taphrogenic structures of the rift phase and were supplied by marine water from a central graben, by passing an external barrier; $b$ ) the Paripueira evaporites rest on the continental crust and consequently the continentaloceanic crust contact will be located away from the external saliferous limit; and $c$ ) the Brazilian marginal evaporites would have not been continous with their African counterparts.

Four tectonic-sedimentary evolutive phases were differentiated: intumescence phase (Late Jurassic-Early Cretaceous), when crustal uplift, formation of peripheric basins and deposition of continental sequences took place; rift phase (Neocomian-Barremian), with development of intense taphrogenic activity and formation of a symmetric central graben, along the intumescence axis, adjacent rift valley systems where syn-sedimentation of fluvial-deltaic-lacustrine sequences occurred; transition phase (Aptian), when two evaporitic cycles were deposited in some Brazilian marginal basins; and drift phase (Albian-Recent), when the hinges, shallow platforms, extense homoclinal were developed; thick clastic-carbonatic sequences were deposited; and salt and shale diapirism took place.

Two epochs of major igneous activity occurred: in the Early Cretaceous, associated to the rift phase; and in the Oligocene-Miocene, during the drift phase.
\end{abstract}

INTRODUÇÃO Este trabalho apresenta os resultados de uma análise regional de todas as bacias marginais brasileiras (Fig. 1), destacando aspectos relacionados com o arcabouço estrutural, com a estratigrafia das sequências evaporíticas e com a evolução tectono-sedimentar.

$O$ estudo foi realizado mediante a abordagem dos seguintes assuntos: descrição generalizada, correlação e estabelecimento da relação genética entre as feiçðes mais significativas do arcabouço estrutural-estratigráfico das bacias; elaboração de modelos evolutivos; caracterização e análise de dois ciclos evaporíticos (Paripueira e Ibura) na bacia-tipo Sergipe-Alagoas e correlação com evaporitos de outras bacias marginais brasileiras; e inferências paleogeográficas e esboço de modelos geológicos compatíveis com os resultados analíticos do estudo.

$O$ arcabouço tectônico é definido pelos nove tipos estruturais bastante significativos, de extensão regional: blocos falhados escalonados com basculamento sintético; blocos falhados escalonados com basculamento antitético; zona de inversão estrutural; charneira com grabens de compensação; plataforma rasa; estrutura homoclinal; falha de crescimento com rollover; diápiro de sal e de folhe-

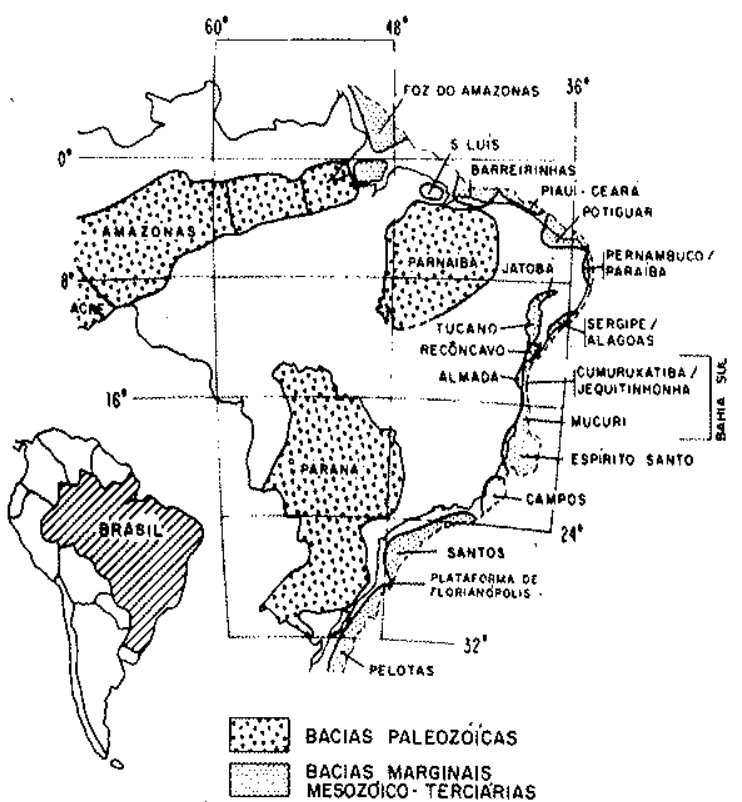

Figura I - Mapa-indice das bacias sedimentares brasileiras 


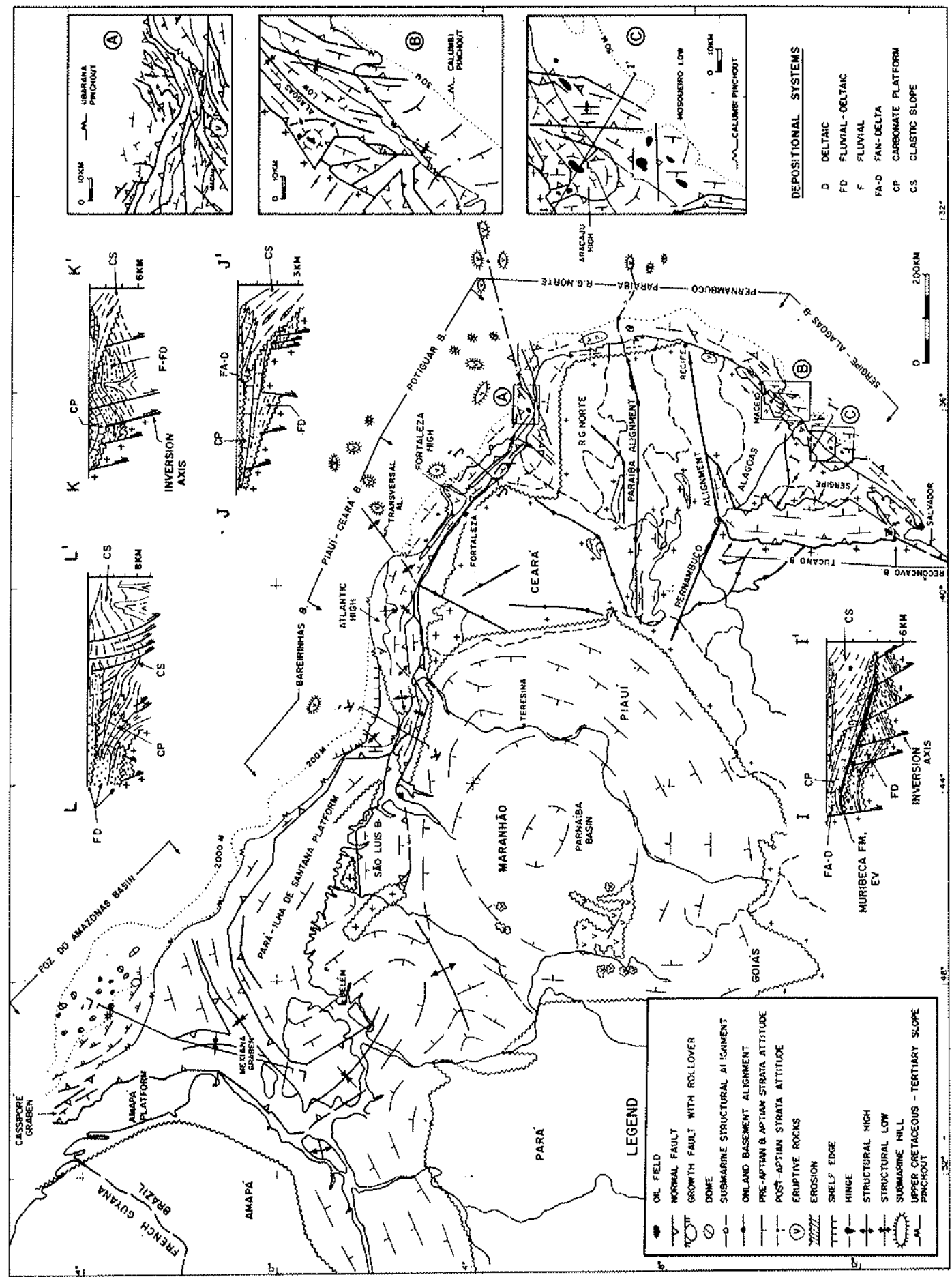




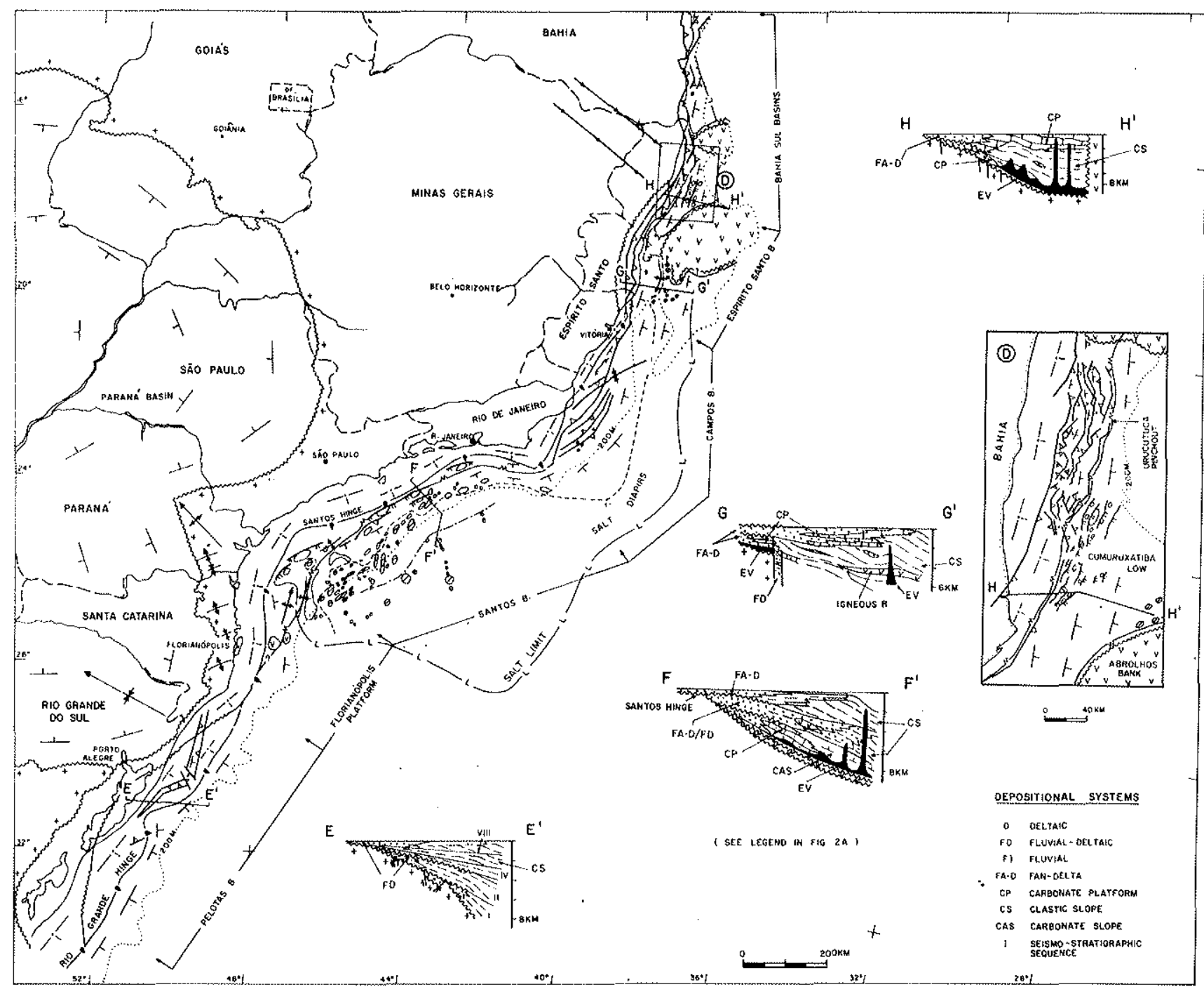

Figura 2B - Mapa tectônico generalizado das bacias marginais brasileiras do centro-leste e sudeste

lho; e feição relacionada com atividade ígnea. O desenvolvimento contemporâneo dos dois sistemas de blocos falhados, separados por uma zona de inversão, constitui um novo enfoque na evolução do arcabouço estrutural das bacias marginais brasileiras e pode constituir-se em objeto de investigação futura em trabalhos de exploração petrolifera ou em estudos oceanográficos.

A análise da sequência evaporítica é outro aspecto importante focalizado neste trabalho. Na bacia-tipo de Sergipe-Alagoas, os evaporitos Paripueira e Ibura representam dois ciclos transgressivos, interrompidos por uma fase regressiva, na qual foi depositada espessa sequência clástica não-marinha. Consideraçôes genéticas e paleogeográficas permitem estabelecer que esses evaporitos não devem ter sido contínuos com seus correspondentes africanos.

A relaçăo entre as fácies sedimentares, as estruturas mais significativas e o potencial petrolifero são também discutidos brevemente e, sempre que possfvel, relacionados com as proposiçðes tectónicas e estratigráficas estabelecidas no trabalho.
Para dar suporte a este estudo, foram utilizados relatórios, dados exploratórios (principalmente de poços, sísmicos de reflexão, paleontológicos e geoquímicos) da Petrobrás, bem como outras informaçðes e interpretaçð̃es da literatura geológica especializada.

Trabalhos prévios $O$ arcabouço estrutural-estratigráfico da margem continental brasileira superior foi relativamente pouco estudado até 1968. Muitos dos trabalhos publicados referem-se geralmente às bacias emersas, onde, mediante exploração petrolífera intensa, muitos dados foram obtidos e formuladas múltiplas hipóteses. Na plataforma continental e no talude superior, os dados publicados focalizam só áreas restritas, baseando-se em dados da exploração petrolífera e oceanográfica pioneiras. Butler (1969), Miranda (1970), Baccar (1970) e Rezende (1970) delinearam preliminarmente o arcabouço es. trutural das bacias de Pelotas, Santos e Barreirinhas; e Boyer (1969) discutiu as feiçðes estruturais da margem continental leste brasileira, entre Natal e Rio de Janeiro. 
Desde 1968, a Petróleo Brasileiro S.A. (Petrobrás) realiza agressiva exploração petrolífera na plataforma continental e talude superior, por meio de levantamentos gravimétricos, magnetométricos, sísmica de refração, milhares de linhas de reflexão sísmica, bem como centenas de poços. Paralelamente, foram realizados estudos oceanográficos por várias instituiçōes de pesquisa. A interpretação, principalmente dos dados da Petrobrás, permitiu a definição do arcabouço estrutural básico da plataforma continental e talude superior enquanto as feições além deste limite foram delineadas baseando-se em dados das pesquisas oceanográficas.

Muitos trabalhos foram publicados, desde 1969, por geólogos e geofísicos da Petrobrás e de outras instituiçðes, focalizando a margem continental brasileira. Os que discutem o arcabouço estrutural, geralmente enfatizam falhas, alinhamentos estruturais e extensão de zonas de fraturas; merecendo destaque os seguintes: Barreto e Milliman (1969), Rezende e Ferradaes (1971), Dietz e Holden (1970), Ojeda e Bisol (1971), Miura e Barbosa (1972), Asmus e Porto (1972), Estrella (1972), Zembruscky et al. (1972), Bryan et al. (1972), Ojeda (1973), Ojeda e De Cesero (1973), Ojeda et al. (1973). Asmus e Ponte (1973), Ojeda e Fugita (1974), Campos et al. (1974), Ojeda e Silva (1975), Delteil et al. (1976), Almeida (1976), Mascle e Renard (1976), Gorini e Bryan (1976), Ojeda e Motta (1976), Ojeda (1976), Kumar et al. (1976), Guazelli et al. (1977), Dauzacker e Andrade (1977), Asmus e Carvalho (1977), Milliman (1978) e Gonçalves et al. (1979). Ponte e Asmus (1976 e 1978) publicaram dois excelentes trabalhos resumindo os conhecimentos das bacias marginais brasileiras, com especial ênfase para o arcabouço estrutural estratigráfico e evolação tectono-sedimentar.

$\mathrm{Na}$ área emersa da Bacia de Sergipe, a sequiência evaporítica foi bem estudada por Fonseca (1973) e Szatmari et al. (1974). Esses autores fizeram detalhada descrição dos ciclos evaporíticos e formularam algumas hipóteses relacionadas com sua origem. Leyden e Nunes (1972), Mascle et al. (1973), Rona (1976) e Leyden (1976), entre outros, estudaram as sequências evaporíticas da plataforma e talude continentais, estabelecendo seus limites aproximados e definindo as estruturas diapíricas mais proeminentes.

ARCABOUÇO ESTRUTURAL O arcabouço estrutural das bacias marginais brasileiras é caracterizado por nove tipos de estruturas diastróficas e adiastróficas, tais como: blocos falhados escalonados com basculamento sintético; blocos falhados escalonados com basculamento antitético; zona de inversão do mergulho regional; charneira com grabens de compensação; estrutura homoclinal; plataformas rasas; falhas de crescimento com rollovers; diápiros de folhelho ou sal; e estruturas arqueadas relacionadas a atividade ígnea (Figs. 2 a 6 ).

A distribuição e a relação espacial do arcabouçc estrutural é mostrado nas Figs. $2 A$ e $2 B$. Ali, destacam-se as falhas e a atitude dos estratos como elementos básicos da definição deste arcabouço, ao contrário de trabalhos anteriores, nos quais se confere destaque principal às falhas.

$O$ desenvolvimento deste arcabouço estrutural foi controlado pelos eventos associados à formação e evo- lução das placas Sul-Americana e Africana, entre o Neojurássico e o Recente, por meio das fases de intumescimento e fraturamento do continente Gondwana e das fases de transição (proto-oceânica) e de migração (oceânica) das referidas placas crustais.

$\mathrm{Na}$ discussão do arcabouço estrutural, os pontos que representam novo enfoque são os seguintes: $a$ ) caracterização dos dois sistemas de blocos falhados escalonados com basculamento sintético e antitético, separados por uma zona de inversão; $b$ ) interpretação de sua evolução síncrona ao longo de rift valleys adjacentes e paralelos a um graben central simétrico, ao longo do qual se instalou, na fase proto-oceânica, o golfo marinho que "alimentou" as bacias evaporíticas; e c) admissão da existência de um alto externo, separando o graben central da área de rift valleys, e que no futuro serviria de barreira de restrição das bacias evaporíticas (separando-as do golfo marinho, central).

Principais feições estruturais As feições mais significativas do arcabouço estrutural das bacias marginais brasileiras serão focalizadas em seguida, destacando-se a geometria, a distribuição, a idade e as relaçðes genéticas espaciais e temporais.

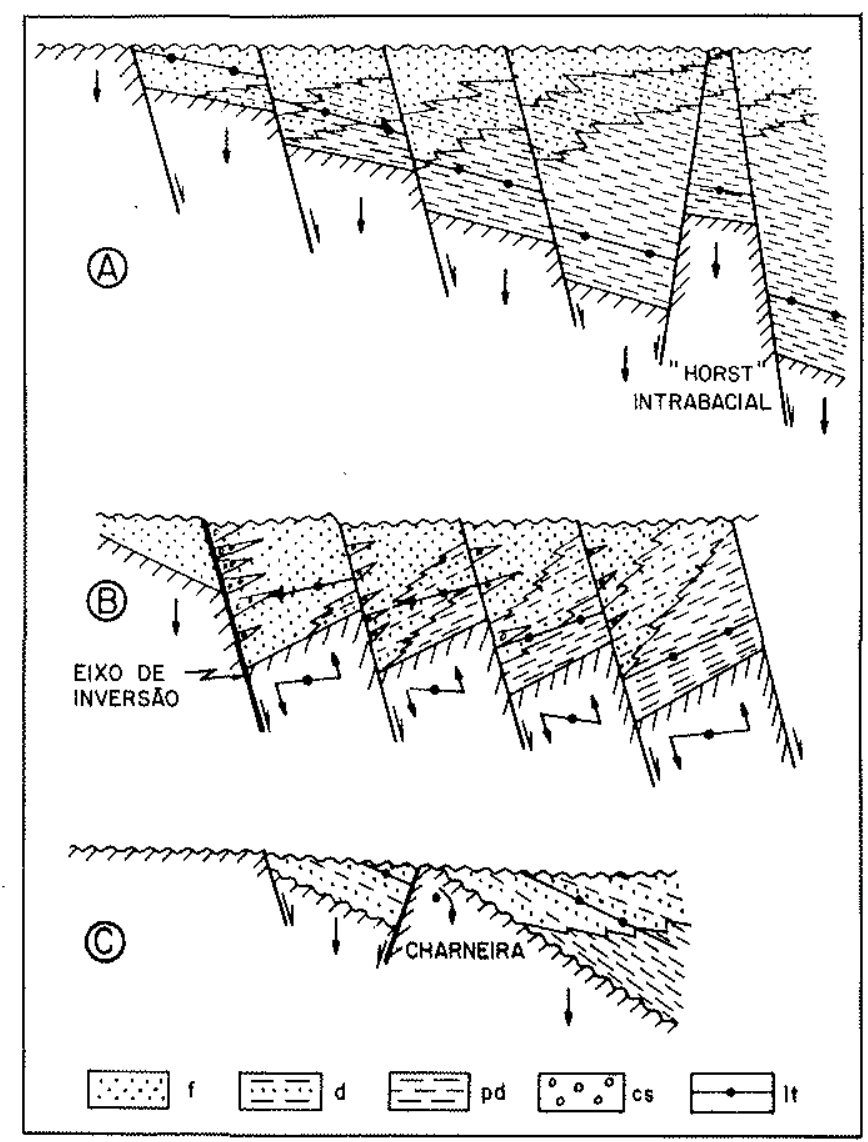

Figura 3 - Principais estruturas diastróficas das bacias marginais brasileiras: $\mathrm{A}$ - blocos falhados escalonados com basculamento sintético (fase rift); B - blocos falhados escalonados com basculamento antitético (fase rift); e $\mathrm{C}$ - charneira com graben de compensação, plataforma rasa e bacia profunda (fase de migração). Sistemas deposicionais: $\mathrm{f}$ - fluvial; $\mathrm{d}$ - deltaico; pd - prodeltaico-água profunda; $\mathrm{sc}$ - conglomerados sintectônicos; e It - linha de tempo 
BLOCOS FALHADOS, ESCALONADOS COM BASCULAMENTO SINTÉTICO Trata-se de estruturas assimétricas, limitadas por falhas normais, com estratos e planos de falhas inclinados para a bacia, acompanhando o mergulho deposicional dos estratos envolvidos (Fig. $3 a$ ). Os blocos de falha apresentam escalonamento bacial crescente, que coloca as fácies distais gradual e relativamente a maiores profundidades que as fácies proximais síncronas. Ocasionalmente, registram-se blocos intrabaciais anômalos, que representam feiçðes estruturais positivas. Este tipo de estrutura é registrado nas bacias da Foz do Amazonas, Potiguar, Sergipe-Alagoas e Barreirinhas (nas áreas marginais, adjacentes ao limite atual da bacia), Recôncavo-Tucano (Fig. 4), Bahia Sul a Pelotas.

Baseando-se nas relaçðes estrutural-estratigráficas e espaciais, admite-se que este sistema tectônico se desenvolveu por meio de deslocamentos descendentes, gradativamente mais acentuados da borda para o centro da bacia. Ocasionalmente, alguns blocos subsidiram menc. que os blocos adjacentes formando horsts síncronos sobre os quais se depositaram seçð̋es sedimentares relativamente menos espessas, às vezes interrompidas por erosão. Como exemplo podem ser citados o horst de Mata-Catu, na Bacia do Recôncavo, e os horsts de Penedo e Japoatã, na Bacia Sergipe-Alagoas.

\section{BLOCOS FALHADOS ESCALONADOS COM BAS-} CULAMENTO ANTITÉTICO Este é um sistema de blocos assimétricos formados por falhas antitéticas mer-

A

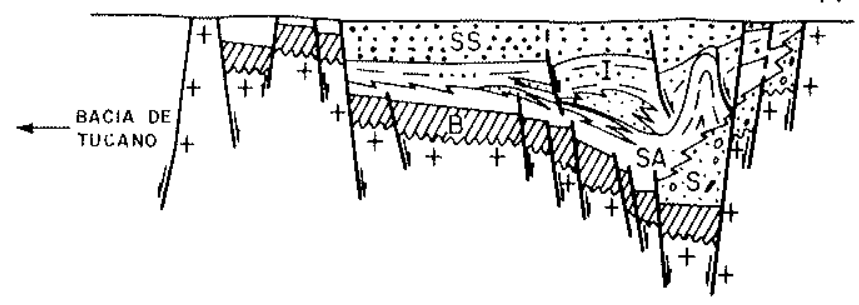

B

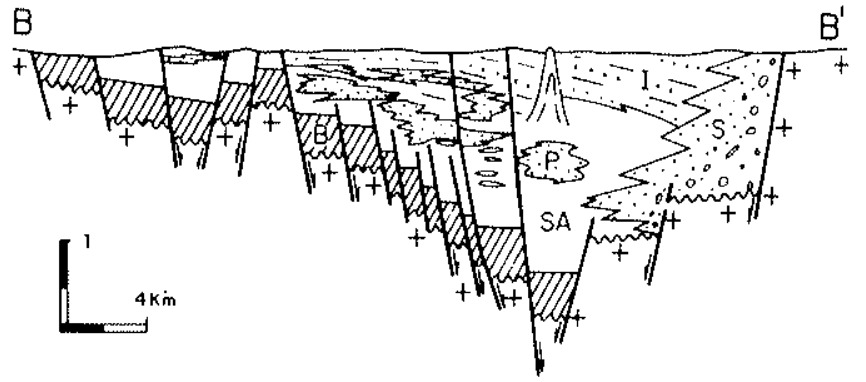

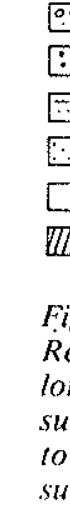

F
F
lo
su
o




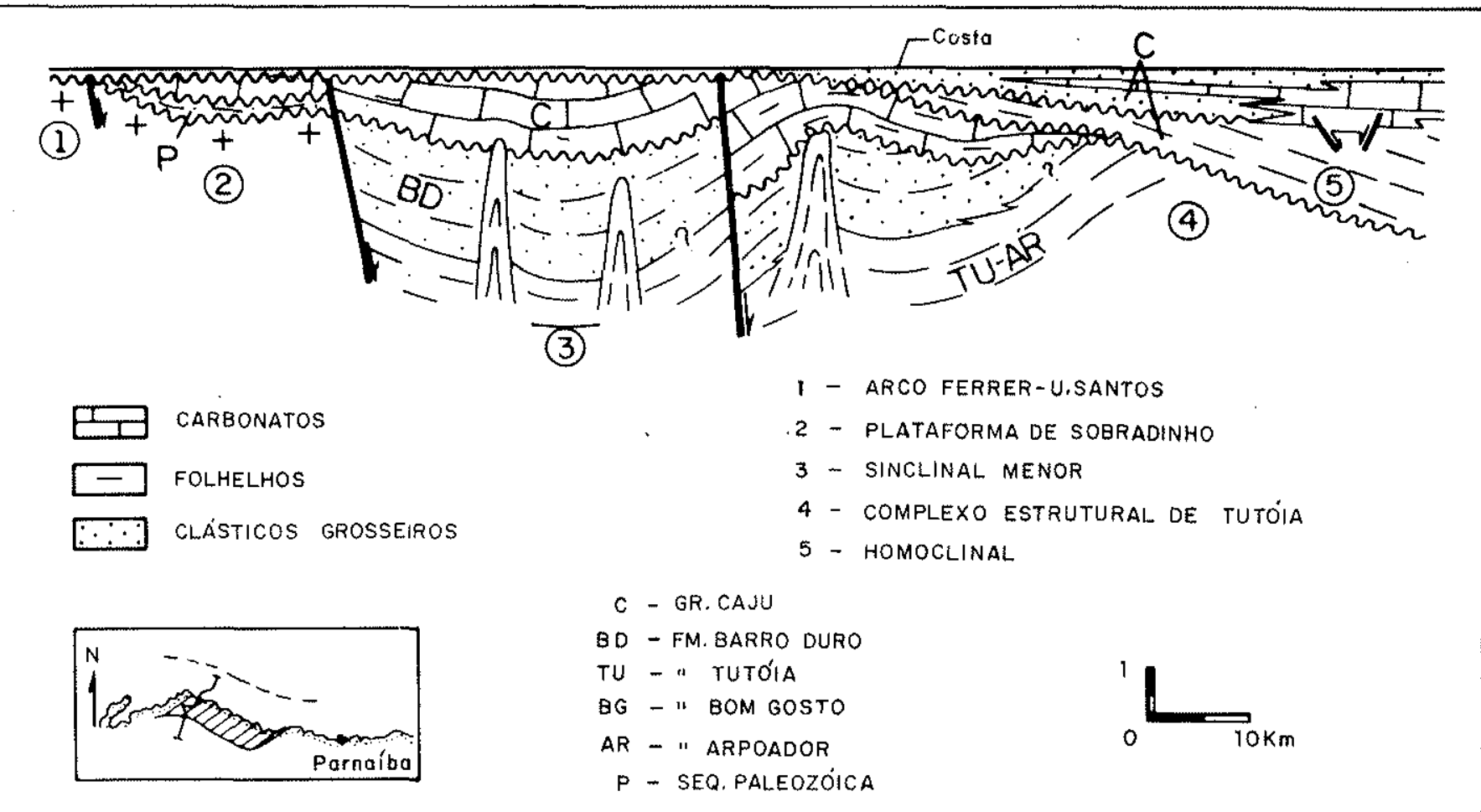

Figura 5 - Seção geologica transversal na Bacia de Barreirinhas, exemplificando o sistema de blocos falhados escalonados com bas. culamento antitético, diápiros e folhelhos e estrutura homoclinal (baseada em dados sísmicos e de subsuperficie)

paralelos e adjacentes à linha de flexura, que são interpretados como feiçðes de ajustamento tectônico necessárias ao restabelecimento do equilíbrio isostático regional.

Esta feição está bem definida nas bacias ao sul de Sialvador (Fig. $2 B$ ), onde constitui importante fator na exploração petrolífera, ao delimitar a parte relativamente menos prospectiva das bacias (plataforma rasa), devido à pequena cobertura sedimentar e fácies geralmente pouco favoráveis da parte profunda mais prospectiva.

A gênese desta estrutura estaria relacionada com a ruptura definitiva e com a migração divergente das placas Sul-Americana e Africana, e com os eventos associados, tais como: crescimento do assoalho oceânico e erupção e resfriamento de magma (com consequientemente aumento do peso). Os esforços resultantes da interação crosta continental-oceânica teriam provocado a ruptura (quebra) da primeira, com desenvolvimento dos grabens de compensação.

PLATAFORMA RASA Trata-se de extensa feição situada aquém da charneira discutida acima, tendo o embasamento relativamente raso (a profundidades que, em geral, não ultrapassam os $2000 \mathrm{~m}$ ), e apresenta suave mergulho para a bacia. A cobertura sedimentar é constituída predominantemente de depósitos terciários e quaternários.

Esta estrutura localiza-se, adjacente, ao longo da costa brasileira, sendo marcadamente extensas as plataformas de Amapá, Pará e Itha de Santana, na margem equatorial (Fig. 2A), Campos, Santos e Pelotas, na margem sul-brasileira (Fig. $2 B$ ).
ESTRUTURA HOMOCLINAL Esta feição ocorre em quase todas as bacias marginais brasileiras sobreposta ao sistema tafrogênico eocretáceo ou ao embasamento cristalino, com mergulho relativamente forte para a bacia (Figs. $2 A$ e $2 B$ ). Na margem sul, o homoclinal inicia-se na linha de charneira, constituindo a bacia profunda (Fig. 2B).

A cobertura sedimentar é representada por espessa cunha de sedimentos clásticos e carbonáticos, não-marinhos e marinhos, albiano-quaternários, correspondentes principalmente a depósitos de leques deltaicos, plataforma e talude (Brown et al., 1974, 1975 e 1976; Fisher et al., 1973, 1974 e 1975; e Ojeda et al., 1973).

Esta feição desenvolveu-se entre o Albiano e o Recente, como resultado dos eventos associados à migração divergente das placas Africana e Sul-Americana (Fig. 11).

\section{FALHAS DE CRESCIMENTO COM ROLLO-} VERS Estas estruturas, associadas à movimentação de sal ou de folhelho, ocorrem na maioria das bacias, de preferência nas da Foz do Amazonas, Barreirinhas, Sergipe-Alagoas, Bahia Sul, Campos e Santos (Figs. $2 A$ e $2 B$ ). Nestas últimas, estas feiçóes distribuem-se ao longo de uma faixa adjacente à charneira, no bloco basculado sinteticamente.

Este tipo de estrutura é considerado bom prospecto petrolífero potencial, devido às seguintes razóes: $a$ ) são estruturas síncronas e precoces, evidenciado pelo adelgaçamento de estratos do flanco para o ápice; e $b$ ) as falhas de crescimento podem constituir o meio de migração do óleo das fácies geradoras profundas para reservatórios lenticulares mais novos e estruturados, carbonáticos e/ou clásticos (Fig. 6a e b). 
DIAPIROS Estas feições são comuns em bacias evaporíticas brasileiras, sob a forma de intumescências e domos perfurantes (Figs. 5 e $6 c$ ). A maioria das intumescências observadas apresenta desenvolvimento sin-sedimentar, com adelgaçamento de estratos para o ápice e fechamento dômico. O recobrimento sedimentar deformado é constituído geralmente por carbonatos ou clásticos albiano-cenomanianos, que constituem bons alvos exploratórios para petróleo.

Os domos perfurantes atingem estratos gradativamente mais novos da borda para o depocentro das bacias. Nas bacias da Foz do Amazonas, Campos, Santos e Espírito Santo (?), esses domos distribuem-se em alinhamentos adjacentes e paralelos ao de "almofadas" e ao limite externo da seqüência carbonática albiano-cenomaniana (Fig. 2B). Deposição concomitante à estruturação é inferida para alguns intervalos estratigráficos, segundo evidências sísmicas.
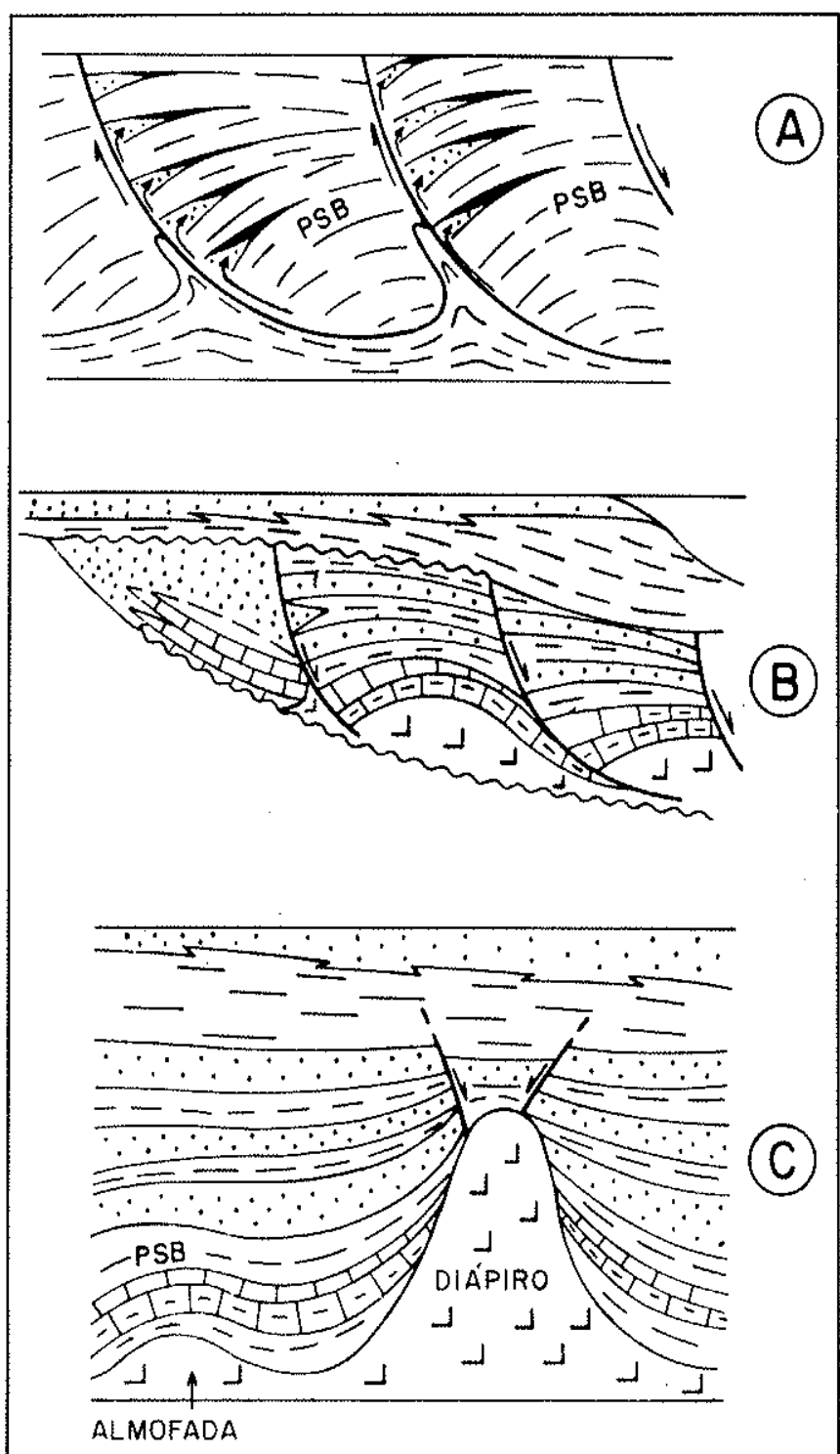

Figura 6 - Principais estruturas adiastróficas das bacias marginais brasileiras: A - falhas de crescimento com rollover (sistema clástico); B - falhas de crescimento com estrutura residual (sistema clástico-carbonato-sal); $\mathrm{C}$ - diápiro de sal com intumescência periférica (sistema clástico-carbonato-sal); $e$ PSB - camadas geradoras potenciais de óleo
ESTRUTURAS IGNEAS São grandes estruturas arqueadas, geralmente de forma dômica, relacionadas com atividade ígnea intrusiva ou extrusiva, contínua ou intermitente, algumas recobertas por espessa seção sedimentar. O núcleo é constituído por basalto ou andesito ocasionalmente intercalado com sedimentos clásticos. As feiçōes mais expressivas deste tipo registram-se nas bacias do Ceará (Alto de Fortaleza), Bahia Sul-Espírito Santo (complexos vulcânicos de Royal Charlote e Abrolhos) e Plataforma de Florianópolis (Figs. $2 A$ e $2 B$ ).

Distribuiçåo e idade das estruturas As feiçoes típicas que formam o arcabouço das bacias marginais brasileiras distribuem-se em faixas adjacentes e subparalelas, da borda para o depocentro das bacias, segundo a seguinte ordem generalizada: borda da bacia, plataforma rasa, charneira, sistema de blocos falhados escalonados com basculamento sintético, zona de inversão, sistema de blocos falhados escalonados com basculamento antitético e estrutura homoclinal. Ainda, esta sequêencia pode ser hipoteticamente completada por um alto externo, parte de um graben central simétrico e crosta oceânica (Figs. $2 A$, $2 B, 3,5,7$ e 11$)$.

Admite-se que os dois sistemas de blocos falhados escalonados se formaram concomitantemente ao desenvolvimento da fase de fraturamento do continente Gondwana, no Eocretáceo (Neocomiano-Barremiano e possivelmente Eoaptiano). Os estratos deformados compreendem sedimentos predominantemente clásticos flúvio-deltaicolacustrinos (às vezes depositados sintectonicamente) e, ocasionalmente, evaporitos.

A charneira e a estrutura homoclinal desenvolveramse na fase de migração divergente das placas Africana e Sul-Americana, basicamente entre o Albiano e o Terciário, propiciando a deposição de espessa cunha de sedimentos clásticos e carbonáticos, correspondentes a depósitos de leques deltaicos e marinhos de plataforma e talude.

Discussão sobre a interpretaçăo gravimétrica $\mathrm{O}$ arcabouço estrutural e a própria distribuição estrutural, ora esboçados, são compatíveis com dados e interpretação gravimétrica, principalmente onde são constatados os dois sistemas de blocos falhados escalonados com basculamento sintético e antitético. Na Bacia de Sergipe, por exemplo, o mapa Bouguer (Fig. 8) mostra acentuado "efeito de borda", evidenciado por progressivo aumento de valores positivos a partir de fortes alinhamentos negativos localizados em terra, seguindo conhecidos baixos estruturais. Este fato é facilmente explicável considerando o sistema basculado antiteticamente, que coloca o embasamento cristalino a profundidades menores e está mais próximo da crosta oceânica que o sistema basculado sinteticamente (Fig. 11).

Comportamento similar é observado na Bacia de Barreirinhas e atribuído às mesmas causas. Em outras bacias marginais brasileiras, o mapa Bouguer nao mostra o referido "efeito de borda" dentro dos limites da atual plataforma e talude superior, devendo manifestar-se, porém, além deste limite. Evidenciam-se, apenas, anomalias positivas "simétricas", atribuídas a altos intrabaciais do sistema de blocos falhados com basculamento sintético. 


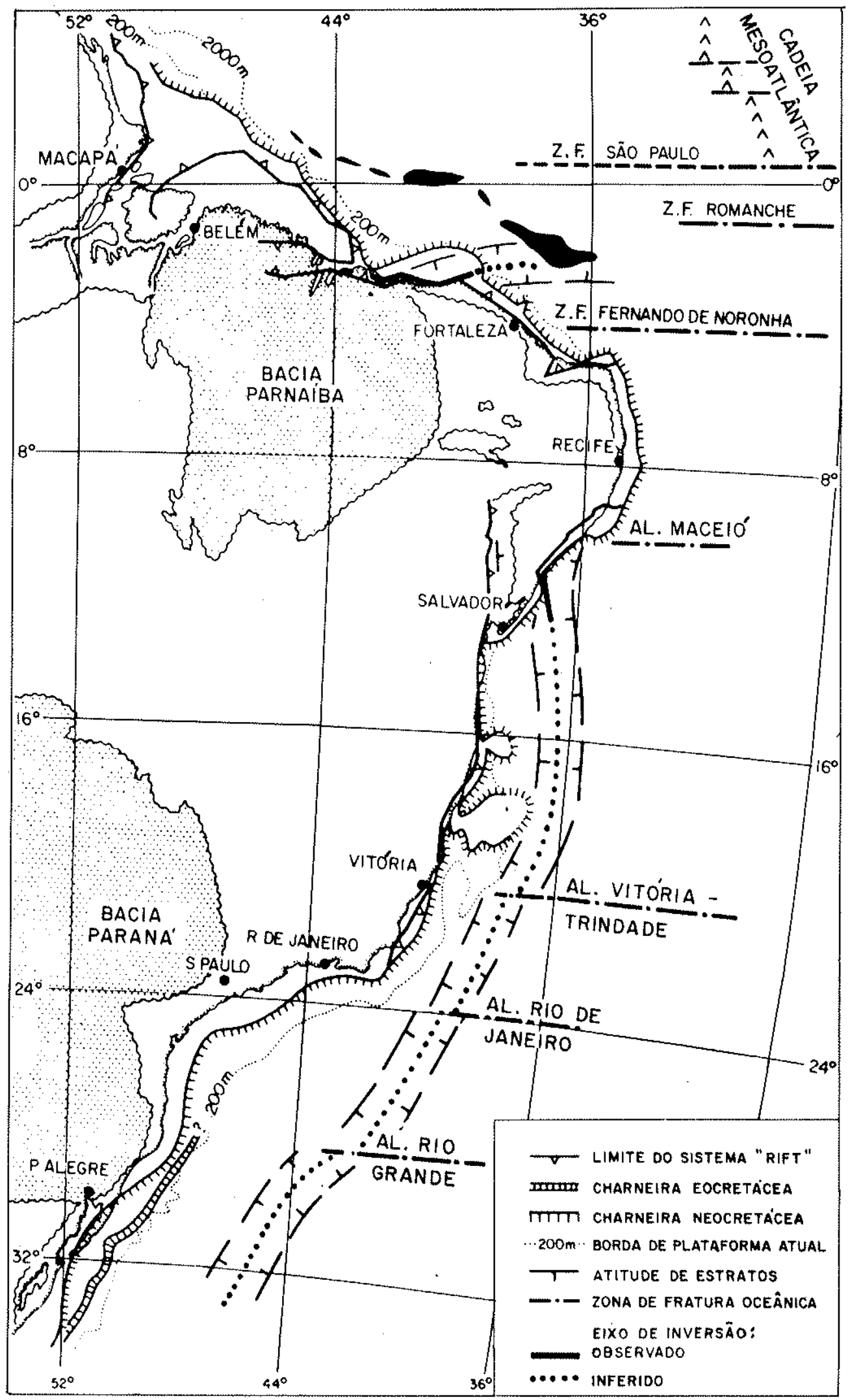

Figura 7 - Esboço tectônico da margem continental brasileira: áreas pontilhadas - bacias paleozócas; ZF - zona de fratura oceânica; e AL - alinhamento estrutural 


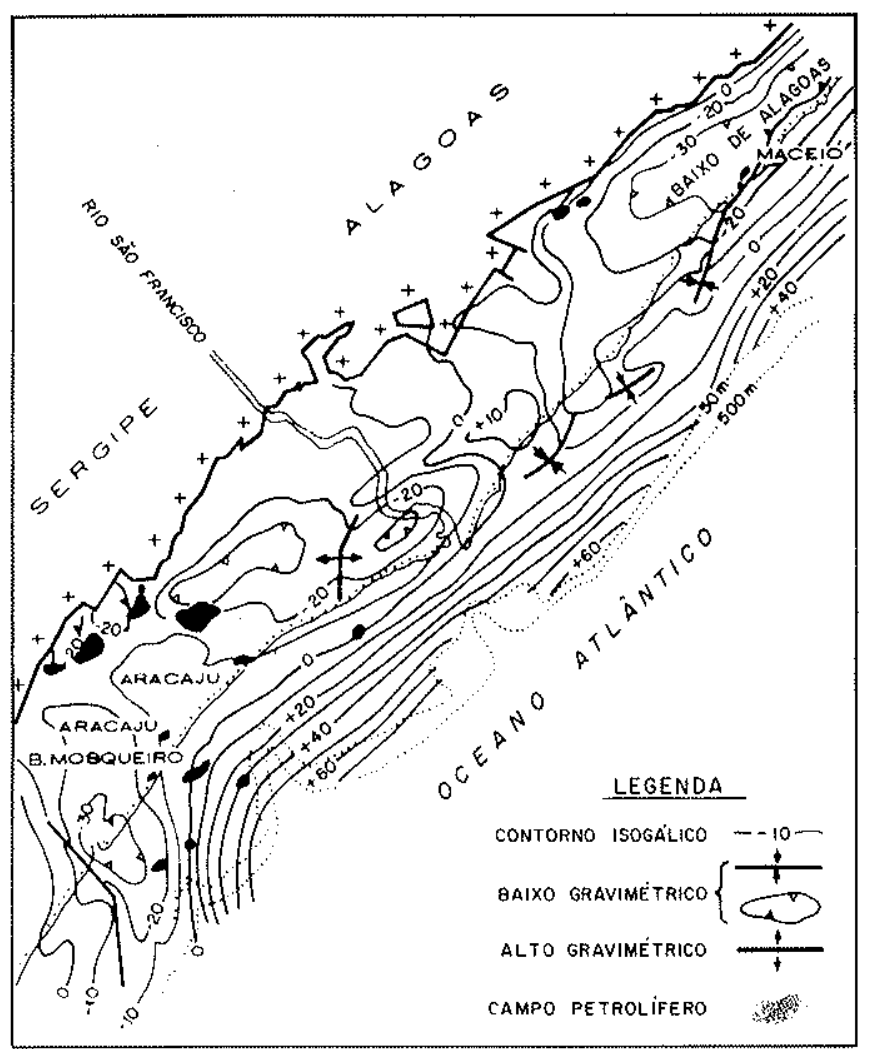

Figura 8-Mapa de Bouguer da Bacia de Sergipe-Alagoas

SEQUUÊNCIA EVAPORÍTICA A maioria das bacias marginais brasileiras registra uma seção evaporítica localizada entre as seqüências flúvio-deltaica-lacustrina, da fase rift principal, e marinha, da fase de migração das placas (Fig. 9). Essa seção de transição é constituída por evaporitos e sedimentos clásticos e carbonáticos ou, simplesmente, por estes últimos intercalados com finas camadas de anidrita.

A ênfase dada à análise da seqüência evaporítica é decorrente dos seguintes atributos: $a$ ) é um excelente marco separador de fases tectônicas; $b$ ) é um bom meio de correlação e sincronização entre bacias; e c) constitui provado elemento condicionante de acumulação petrolífera, servindo como gerador e selante.

Muitos autores (entre os quais Ponte, 1971; Wenger, 1973; Rona, 1976; Mascle e Renard, 1976; e Evans, 1978) tếm publicado trabalhos sobre esta sequência evaporítica da margem continental brasileira, focalizando aspectos estruturais, distribuição e correlação com seus equivalentes africanos. Neste trabalho, entretanto, dá-se ênfase a alguns aspectos pouco focalizados, tais como: caracterização e discussão de dois ciclos evaporíticos; descontinuidade deposicional com os evaporitos da margem africana ocidental; e aplicação de modelo deposicional constituído por golfo marinho localizado ao longo de um graben central, que "alimentou" bacias evaporiticas situadas (fora do mesmo) nos rift valleys remanescentes.

Estratigrafia Baseando-se em dados de centenas de poços, tais como, descrição de milhares de metros de amostras de calha e testemunhos, e análisé de registros elétricos e radiativos na Bacia de Sergipe-Alagoas, foram diferenciados dois ciclos evaporíticos: evaporitos Paripueira e evaporitos Ibura, bastante distintos principalmente na litologia e nas relaçðes estratigráficas. Esses evaporitos têm sido estudados por muitos geólogos e químicos e geoquímicos, destacando-se os trabalhos de Fonseca (1973) e Szatmari et al. (1974). As consideraçðes acima referidas permitem tomar a Bacia de Sergipe-Alagoas como bacia-tipo para as sequências evaporíticas.

EVAPORITOS PARIPUEIRA Esse ciclo corresponde às "Camadas de Evaporitos Paripueira", da parte inferior do Membro Maceió da Formação Muribeca, na Bacia de Alagoas (Schaller, 1969) (Fig. 10). É composto por halita com intercalaçð̃es de calcário cinza-escuro a preto, siltitos, arenitos e conglomerados intercalados em intervalo estratigráfico até de $1000 \mathrm{~m}$. Na Bacia de Sergipe, os evaporitos Paripueira encontram-se bem diferenciados no intervalo $3475-3560 \mathrm{~m}$ do poço 1-MO-1-SE (Mosqueiro), separados dos evaporitos Ibura por $600 \mathrm{~m}$ de clásticos.

Os evaporitos Paripueira são considerados de Idade Eoaptiano, baseando-se em alguns dados paleontológicos e, principalmente, por se encontrarem sotopostos aos evaporitos Ibura, neoptianos e deles separados pela referida seção de $600 \mathrm{~m}$ de sedimentos clásticos.

A extensão desses evaporitos para as outras bacias do sudoeste brasileiro é especulativa, e baseada principalmente em inferências paleogeográficas, geológicas e geofisicas. Assim, admite-se que os equivalentes dos evaporitos Paripueira estariam situados além da borda da plataforma atual e ainda não atravessados pelas perfuraçð̃es exploratórias petrolíferas. Por exemplo, na Bacia de Santos, este equivalente seriam os alinhamentos diapíricos localizados sob o talude atual e geograficamente separados dos evaporitos Ibura (situados sob a atual plataforma continental) por extensa faixa aparentemente sem sal (Baccar, 1970; e Ojeda e De Cesero, 1973).

EVAPORITOS IBURA Este ciclo, que constitui o Membro Ibura da Formação Muribeca, está bem desenvolvido e faciologicamente multivariado na Bacia de Sergipe. Geralmente, sobrepõe-se à seção dos conglomerados do Membro Carmópolis (que repousa sobre uma discordância angular: a Discordância Pré-aptiana) (Schaller, 1969; e Fugita, 1974). Na Bacia de Alagoas, os evaporitos Ibura compreendem só uma camada de anidrita, que recobre espessa seção dos Conglomerados Carmópolis (Fig. 10).

Os evaporitos Ibura são compostos de camadas de anidrita, carnalita, silvinita e taquidrita, com intercalaçð̌es de folhelhos marrom e calcários laminados (Fonseca, 1973; e Szatmari et al., 1974). No topo da seção evaporítica, ocorrem duas camadas de extensão regional de anidrita brechoide (Marco 38) e nodular (Marco 39) com matriz calcilutítica, que representam depósitos de $s a b k$ ha. Na Bacia de Sergipe, essas camadas de anidrita acham-se mineralizadas com enxofre nativo estratiforme (Ojeda et al., 1979). Os tipos de sais já citados e, principalmente, essas anidritas (de sabkha) são depósitos de água rasa, devendo não ter sido contínuos com seus equivalentes africanos. 


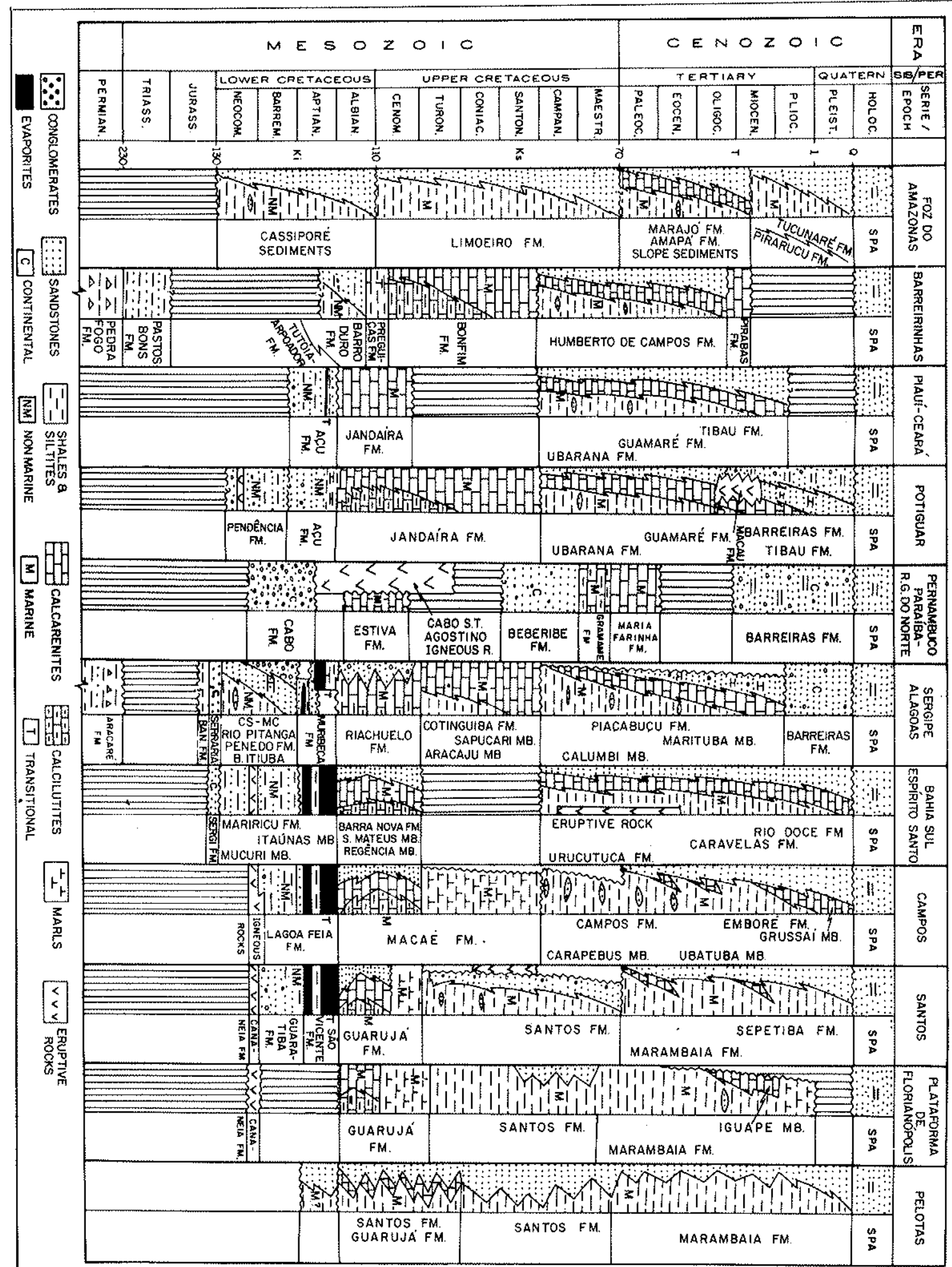


A Formação Muribeca é formalmente considerada de Idade Alagoas (aproximadamente incluída no Aptiano) (Schaller, 1969). À base da Formação Riachuelo (folhelhos e calcários), tipicamente marinha, em contato concordante com a Formação Muribeca, foi-lhe atribuída Idade Neoaptiano, baseando-se na identificação de fósseis diagnósticos, tais como: amonóides, foraminiferos e nanofósseis. Assim sendo, o Membro Oiteirinhos, com segurança, e os evaporitos Ibura, provavelmente, devem ser de Idade Neoaptiano e, consequientemente, o resto da Formação Muribeca (incluindo os evaporitos Paripueira) de Idade Eoaptiana.

CORRELAÇÃO Baseando-se em dados litológicos, paleontológicos, posição e relaçōes estratigráficas; os evaporitos Ibura são correlacionados com as seçðes evaporíticas da área proximal e média das outras bacias marginais leste-brasileiras, bem como das bacias interiores do norte e nordeste brasileiro. Os equivalentes dos evaporitos Ibura, tal como na Bacia de Sergipe, recobrem seção de conglomerados policompostos, assentados sobre uma discordância angular pré-aptiana.

Os evaporitos Ibura são considerados equivalentes das seguintes unidades: Membro Itaúnas da Formação Mariricu, nas bacias de Espírito Santo, Bahia Sul, Campos e Santos; Formação São Vicente, na Bacia de Santos; Formação Santana, na Bacia de Araripe; e Formação Codó, na Bacia de Parnaíba (Figs. $2 A, 2 B$ e 9).

SINCRONIZAÇÃO As unidades equivalentes dos evaporitos Ibura são consideradas de Idade Neoaptiana devido a seu conteúdo fossilífero (Fig. 9). Entretanto, algumas consideraçðos relativas aos evaporitos São Vicente da Bacia de Santos devem ser destacadas: quando Ojeda e De Cesero os definiram, em 1973, consideraram-nos de Idade Aptiana-Barremiana, baseados na presença da superzona palinologica Exesipolennites tumulus (PC-20), a qual é diagnóstica deste período na bacia-tipo de SergipeAlagoas (Schaller, 1969; e Regali et al., 1974). Esses dados levaram a interpretar a fenda entre as placas SulAmericana e Africana progredindo de sul para norte.

Estudos posteriores realizados pela Petrobrás mostraram que esses evaporitos são de Idade Neoaptiana e, portanto, síncronos dos evaporitos Ibura. Mas alguns comentários são necessários: 1) a superzona $\mathrm{PC}-20$ permanece formalmente como diagnóstica do Aptiano-Barremiano na Bacia Sergipe-Alagoas; 2) esta superzona não é diagnóstica para esta idade nas bacias de Campos e Santos, onde fósseis diagnósticos do Albiano foram encontrádos nos mesmos intervalos; 3) os fósseis encontrados nos calcários da Formação Guarujá, Macaé e Regência, respectivamente, nas bacias de Santos, Campos e.Espírito Santo, indicam Idade Albiana (Fig. 9). Assim sendo, os evaporitos sotopostos concordantemente serão aptianos e síncronos com os evaporitos Ibura da Bacia de SergipeAlagoas; e 4) algas vermelhas solenoporáceas (tal como as de Sergipe-Alagoas) foram registradas nos calcários Guarujá, Macaé e Regência, corroborando sua idade albiana.

EVOLUÇÃO TECTO-SEDIMENTAR A evolução tectono-sedimentar das bacias marginais brasileiras tem sido descrita por muitos autores, quase sempre baseados na

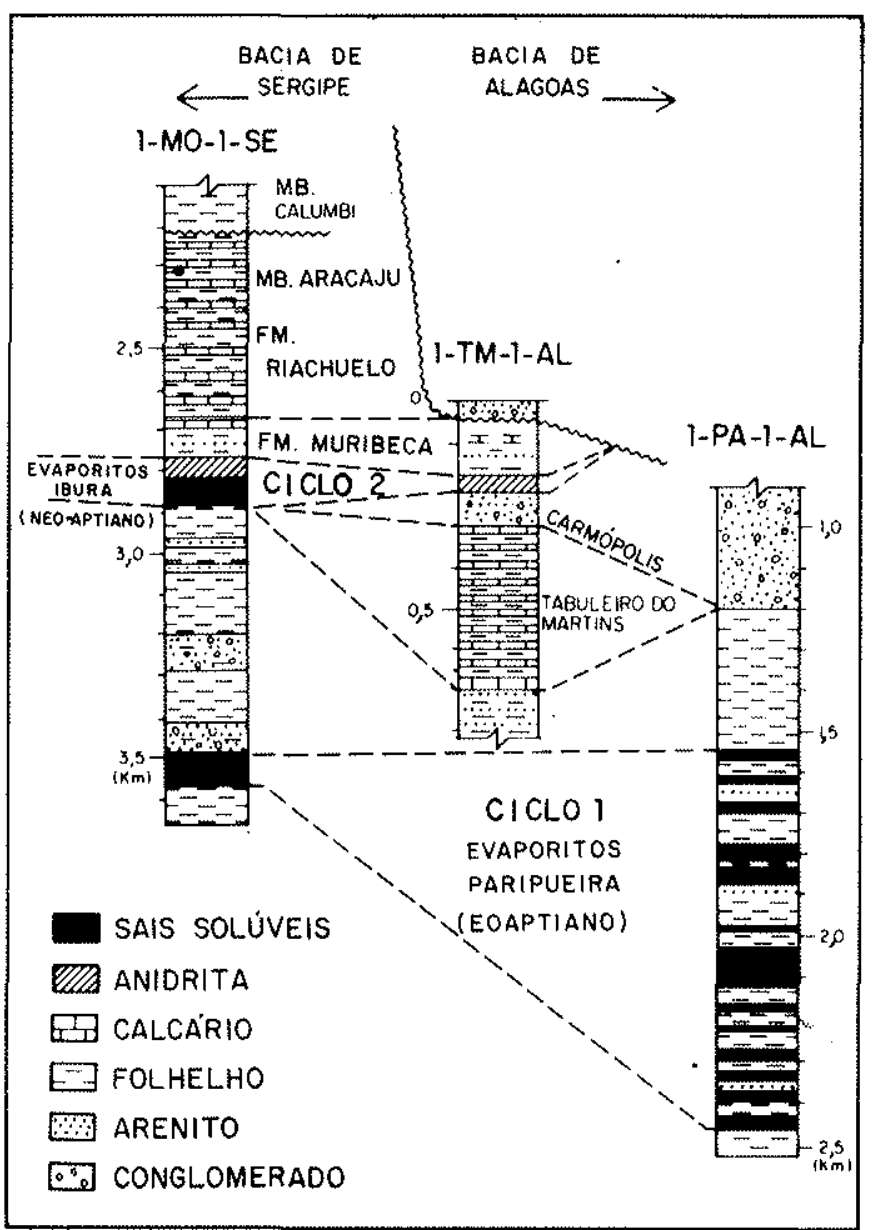

Figura 10 - Correlação estratigrafica dos evaporitos Paripueira (Ciclo l) e evaporitos Ibura (Ciclo 2), na Bacia-tipo de Sergipe-Alagoas

tectônica de placas. Quatro fases evolutivas são normalmente destacadas: fase de intumescência (soerguimento crustal), fase trafrogênica ou de fraturamento (rift), fase transicional e fase de migração. Em cada trabalho foram introduzidas modificaçðes relacionadas com o início da intumescência, quebra definitiva da crosta e ligação entre os oceanos sul-Atlântico e equatorial.

Neste trabalho é feita uma revisão geral, dando-se ênfase aos eventos das fases de fraturamento e transicional, e introduzindo os conceitos do modelo estrutural-estratigráfico previamente discutido (Figs. 11 a 16).

Fase de intumescência Nesta fase, durante o Neojurássico-Eocretáceo, ocorreram eventos que precederam o fraturamento da crosta continental, tais como soerguimento crustal e desenvolvimento de bacias periféricas (Estrella, 1972) (Fig. 11a).

Esse levantamento teve intensidade variável ao longo da margem continental, com grande atividade ígnea local relacionada com hot spots (Morgan, 1971). Nas bacias periféricas foram depositados sedimentos flúvio-deltaicolacustrinos, tais como os das formaçðes Aliança, Sergi e Itaparica da Bacia do Recôncavo-Tucano, e Bananeiras, Serraria e Barra de Itiúba inferior, na Bacia de SergipeAlagoas (Fig. 9). 


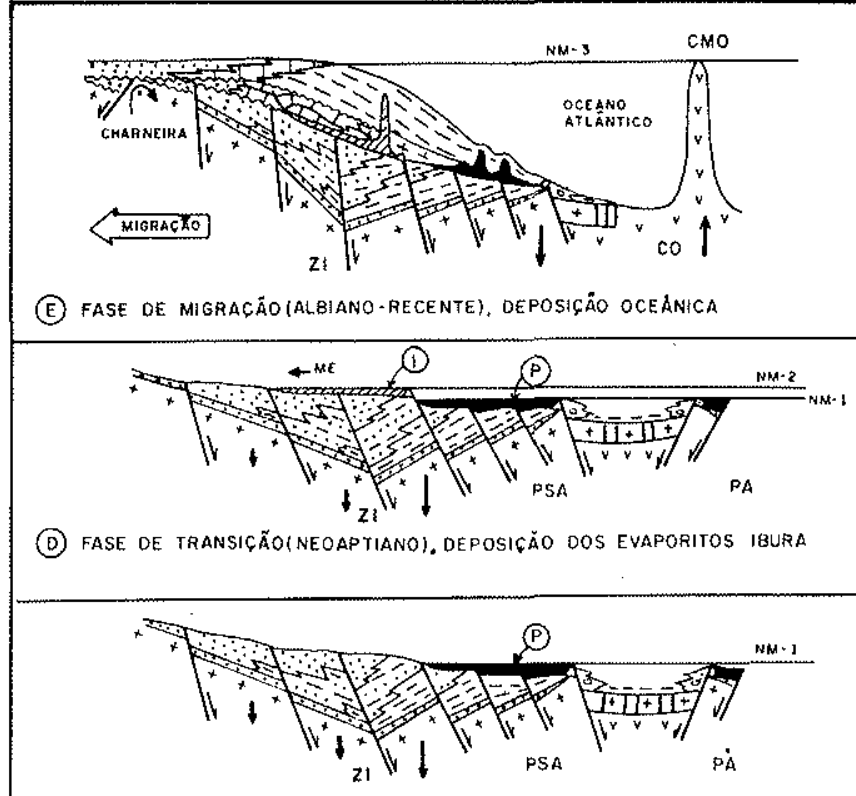

(C) FASE DE TRANSIGAO (EOAPTIANO). DEPOSIGÃO DOS EVAPORITOS PARIPUEIRA

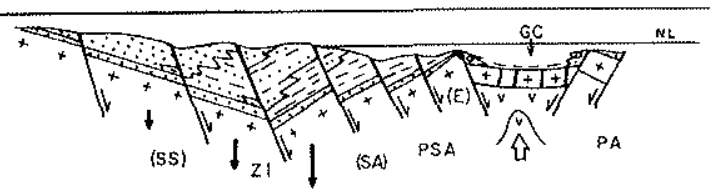

(B) FASE DE FRATURAMENTO(EOCRETÁCEO). DEPOSICÁO LACUSTRE

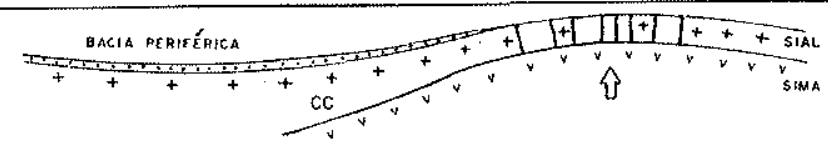

(A) FASE dE INTUMESCE்nCiaineOJURÁSSICO-EOCRETÁCEO)

Figura 11 - Evoluçäo tectônica esquemática da margem leste brasileira: SS - sistema de blocos falhados com basculamento sintético; SA - sistema de blocos falhados com basculamento antitético; $\mathrm{E}$ - alto externo; $\mathrm{GC}$ - graben central; $\mathrm{Z}$ - zona de inversão; $\mathrm{CC}$ - crosta continental; $\mathrm{CO}$ - crosta oceânica; CMA - cadeia Meso-Atlântica; PA - placa Africana; PSA - placa Sul-Americana; 1 - evaporitos lbura; $\mathrm{P}$ - evaporitos Paripueira; $\mathrm{NL}$ - nivel do lago; NM - nivel do mar; $e$ $\mathrm{ME}$ - migraçáo de ambientes evaporíticos

Fase de fraturamento Nesta fase evolutiva, desenvolvida no Eocretáceo (Neocomiano-Barremiano) e estendendo-se até o Neocretáceo (Cenomaniano) na margem equatorial, houve intensa atividade tectônica, com fraturamento de áreas previamente soerguidas e formação de um graben central possivelmente simétrico (ao longo do eixo de intumescimento) e de rift valleys assimétricos, distribuídos adjacentes e paralelamente a ambos lados deste graben, cobrindo parte das antigas bacias periféricas (Figs. 11 e 12).

$\mathrm{Na}$ área de rift valleys, formoumse o arcabouço básico das bacias da margem continental brasileira, com o desenvolvimento síncrono dos dois sistemas de blocos falhados escalonados com basculamento sintético e antitético, unidos pela zona de inversão. Ao mesmo tempo ocorria ativa sedimentação flúvio-deltaico-lacustrina. $O$ eixo de inversão representa áreas de máxima subsidência, si-

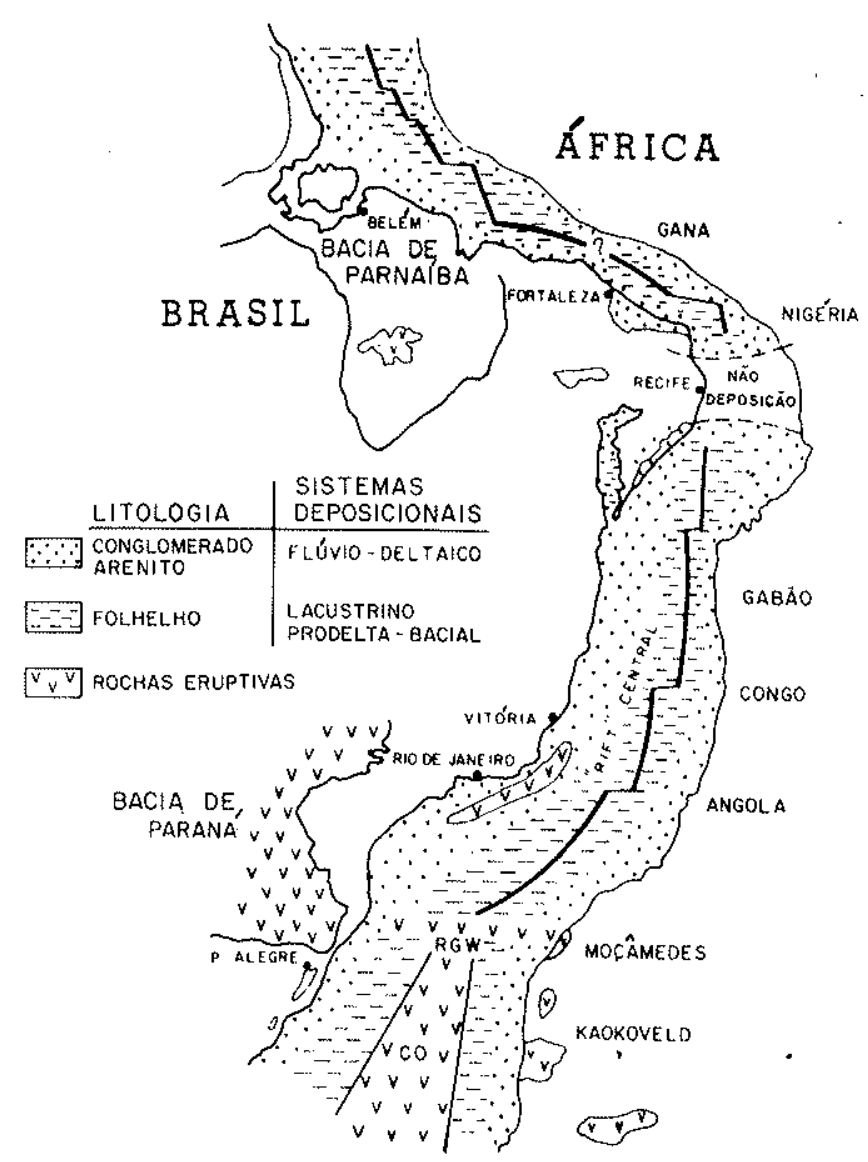

Figura 12 - Esboço paleogeográfico no final do Eocretáceo (Pré-aptiano). Deposição flúvio-deltaico-lacustrina ao norte do alinhamento Rio Grande-Walvis (RGW); deposição marinha ao sul do mesmo. $\mathrm{CO}$ - crosta oceânica

tuada entre o graben central e a área estável do embasamento cristalino (não afetada por movimentos crustais da tectônica de placas, onde se localizavam as áreas-fonte de detritos) (Fig, 11b). Conseqüentemente, o sistema de blocos falhados com basculamento sintético encontrar-se-á, normalmente, nas áreas proximais das bacias ora focalizadas.

A sedimentação ocorreu em bacias lacustrinas alongadas, tipo rift valleys, controladas por estruturas de meiograben, em evolução concomitante. Assim, as culminâncias estruturais constituiam barreiras intrabaciais, que geraram sub-baciais e balizaram parcialmente os sistemas deposicionais e a distribuição faciológica. Como exemplos, bem estudados, podem-se citar as bacias de Barreirinhas e Sergipe-Alagoas.

$O$ registro sedimentar consiste principalmente em clásticos fínos a grosseiros; de origem flúvio-deltaico-lacustrina. Conglomerados sintectônicos, tais como de Rio Pitanga e Salvador, nas bacias do Recôncavo e SergipeAlagoas, respectivamente, foram depositados concomitantemente ao desenvolvimento de grandes falhas (Figs. $2 B$ e 9 ).

Os conjuntos deposicionais proximais (fluvial e deltaico) normalmente são afetados pelo sistema de blocos falhados escalonados com basculamento sintético, enquanto os outros conjuntos (prodelta e bacial) são afetados 
pelo sistema de blocos falhados com basculamento antitético. As bacias de Sergipe-Alagoas e Barreirinhas são exceções, já que fácies proximais se encontram bascula das antiteticamente (Fig. 5).

Atividade ígnea desta fase é representada por extrusões basálticas e andesíticas, nas bacias de Santos, Campos, Bahia-Sul, Espírito Santo e Potiguar.(Figs. 2A, $2 B$ e 9).

Fase de transiçăo Esta fase, desenvolvida no Aptiano, é caracterizada por extensos depósitos sedimentares transicionais (evaporitos, clásticos e carbonatos), que representam a passagem do regime tectônico de intensa trafrogenia para a fase de basculamento para a bacia e deformação adiastrófica da fase de migração continental divergente. Os estágios de deposição dos evaporitos Paripueira e Ibura ocorreram no Eoaptiano e Neo-aptiano; respectivamente, e podem ser assim descritos:

a) EOAPTIANO - Neste período, a barreira topográfico-vulcânica de Rio Grande-Walvis foi ultrapassada por águas marinhas (vindas do oceano localizado ao sul) inundando o graben central e formando um extenso golfo denominado "Golfo Paripueira", que se estendeu até a latitude do limite norte da Bacia Sergipe-Alagoas. Este golfo serviu de acesso e alimentação de água marinha para as bacias evaporíticas situadas fora de seus limites (na área de rift valleys), separadas por uma barreira de restrição (alto externo). Conseqüentemente, este golfo não cobriu a Bacia do Recôncavo-Tucano e as bacias localizadas soh a atual plataforma continental, exceto a Bacia de Alagoas. Nesta bacia, aliás, houve deposição de evaporitos Paripueira ao longo de rift valleys, ainda ativos, segundo e atestado pelo registro de evaporitos intercalados com conglomerados sintectônicos, no sistema de blocós falhados escalonados basculados antiteticamente (Fig. $2 A$, seçan $\left.I-I^{\prime}\right)$.

( ‘umn resultado da invasão de água salgada vinda do Golio Paripueira (através de barreira) e da forte evaporação nas bacias restritas, foi alcançado o estágio de salmoura e ocorreu a precipitação seletiva de sais (principalmente halita, $\mathrm{NaCl}$ ) constituintes dos evaporitos Paripueira (Figs. 11c e 13). Em seguida, houve uma regressão generalizada, quando se depositou a espessa seção clástica transicional interposta entre os evaporitos Paripueira e Ibura (Fig. 10). Por outro lado, nesta mesma época, áreas proximais emersas adjacentes às bacias evaporíticas eram submetidas a intensa erosăo, que removeu grande parte dos sedimentos eocretáceos mais velhos, às vezes atingindo o embasamento (Fig. 11d). Exemplos deste processo encontram-se bem registrados nas bacias de Sergipe, Espírito Santo e Campos (Schaller, 1973).

$\mathrm{Na}$ margem equatorial, houve apenas sedimentação, flúvio-deltaico-lacustrina, controlada por grabens assimétricos desenvolvidos concomitantemente. $O$ registro litoestratigráfico desta fase é o seguinte: "Sedimentos Cassiporé", formaçð̌es Barro Duro e Arpoador na Bacia de Barreirinhas e Formação Pendência na Bacia Potiguar (Fig. 9). Na Bacia Potiguar, o sistema tafrogênico da área emersa (grabens de Apodi e Pendência, e horst de Quixaba), iriterpretado por Asmus (1979) como "Junção Tríplice", continuou sua evolução, já iniciada no Neocomiano (ver Bacia Potiguar, Fig. 2A).

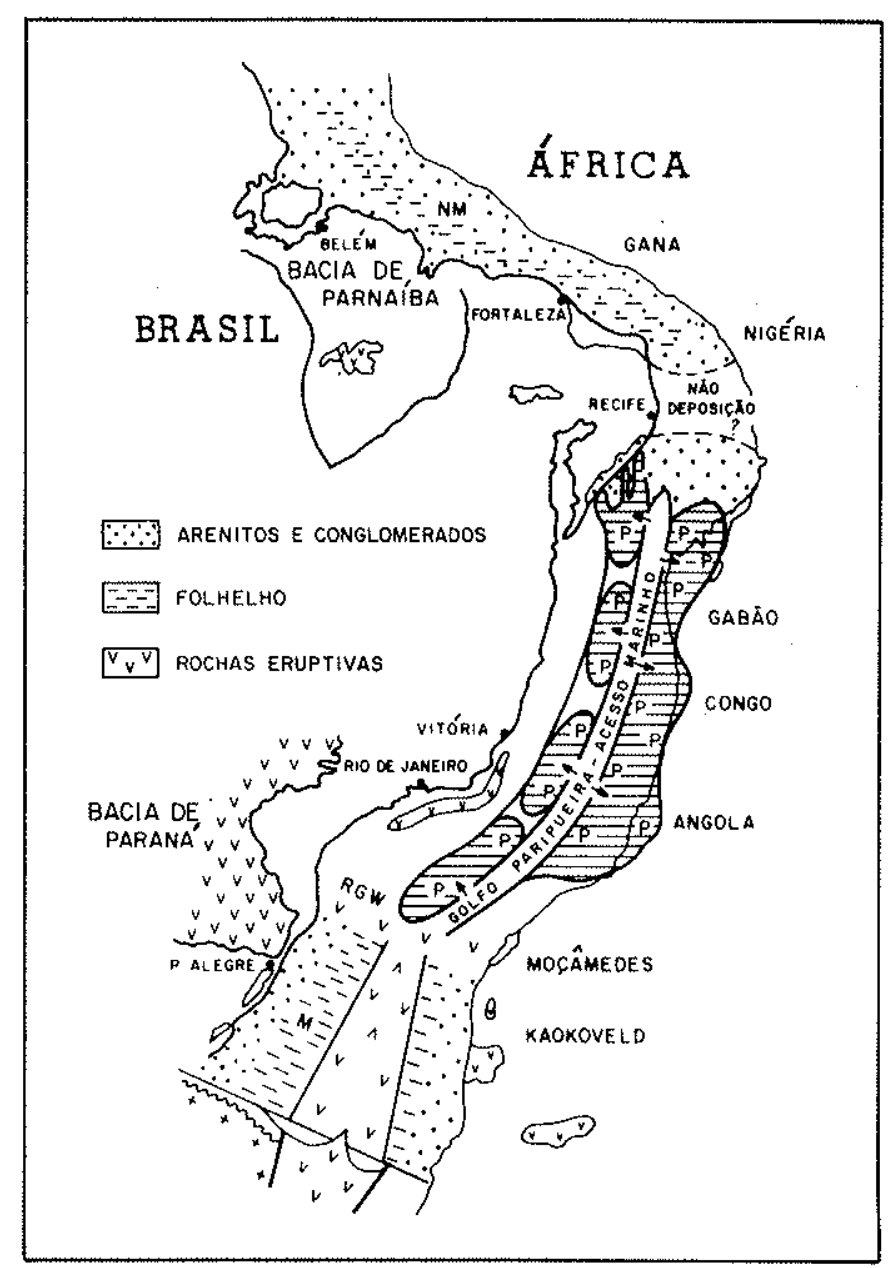

Figura 13 - Esboço paleogeográfico no final do Eoaptiano (Eo-Alagoas). Deposição clástica flúvio-deltaico-lacustrina e evaporitos ao norte da Cadeia Rio Grandè-Walvis (RGW); deposição marinha (M) e crescimento de crosta oceânica $(\mathrm{CO})$, ao sul; NM - ambiente nao-marinho; e P - bacia evaporítica Paripueira

b) NEO-APTIANO - Nesta época, houve sedimentaçăo predominantemente evaporítica (evaporitos Ibura) nas bacias da margem leste brasileira e clástica-lacustrina na margem equatorial (Fig. 14).

$\mathrm{Na}$ margem leste, ao sul da barreira Rio GrandeWalvis, desenvolvia-se mar alto com crescimento de crosta oceânica. Ao norte dessa barreira, ocorria elevação do nivel do mar no Golfo Paripueira e transgressåo generalizada que cobria progressivamente a superficie de erosão do periodo Eoaptiano (por sua vez controlada pelas feições tafrogênicas remanescentes). Desta maneira, formaram-se bacias evaporíticas alongadas, e de tal maneira distribuídas, que deram lugar a uma concentração seletiva das salmouras, com os sais mais solúveis depositados nas bacias mais afastadas do golfo central de alimentação. Excelente exemplo deste modelo observa-se na Bacia de Sergipe, onde os depósitos de silvinita se encontram próximos à borda atual da bacia, na área de Santa Rosa de Lima e Taquari-Vassouras, e os sais menos solúveis (taquidrita, carnalita, halita e anidrita) achamse mais para o depocentro da bacia (Fonseca, 1973; e Szatmari et al., 1974). Ao findar este período, as bacias 
evaporíticas estiveram bastante colmatadas, dando condições para a deposição de extensas camadas de anidrita brechóide (Marco 38) e nodular (Marco 39), em ambientes de sabkha. Essas camadas revestem-se da maior importância geológica, pelas seguintes razóes: $a$ ) são excelentes marcos estratigráficos para correlação regional; b) constituem suporte consistente para inferir que os evaporitos Ibura foram depositados em ambientes restritos marginais rasos, sendo descontinuos portanto com seus correspondentes africanos; e c) såo rocha hospedeira para mineralização de enxofre nativo estratiforme na Bacia de Sergipe (depósito de Castanhal) (Fonseca, 1973; Szatmari et al., 1974; e Ojeda et al., 1979).

Na margem equatorial, o rẹgistro estratigráfico do Neo-aptiano é representado por sedimentos flúvio-deltaico-lacustrinos depositados em rift valleys ainda ativos. Deve-se destacar, entretanto, que a presença de espessa camada de halita neo-aptiana (Idade Alagoas) registrada nas bacias de Ceará e Tacutu poderia ser explicada pela existência de um golfo equatorial (similar ao Golfo Paripueira, embora mais novo), necessário ao fornecimento de água marinha com sais dissolvidos em quantidade compatível com as centenas de metros de halita registradas.

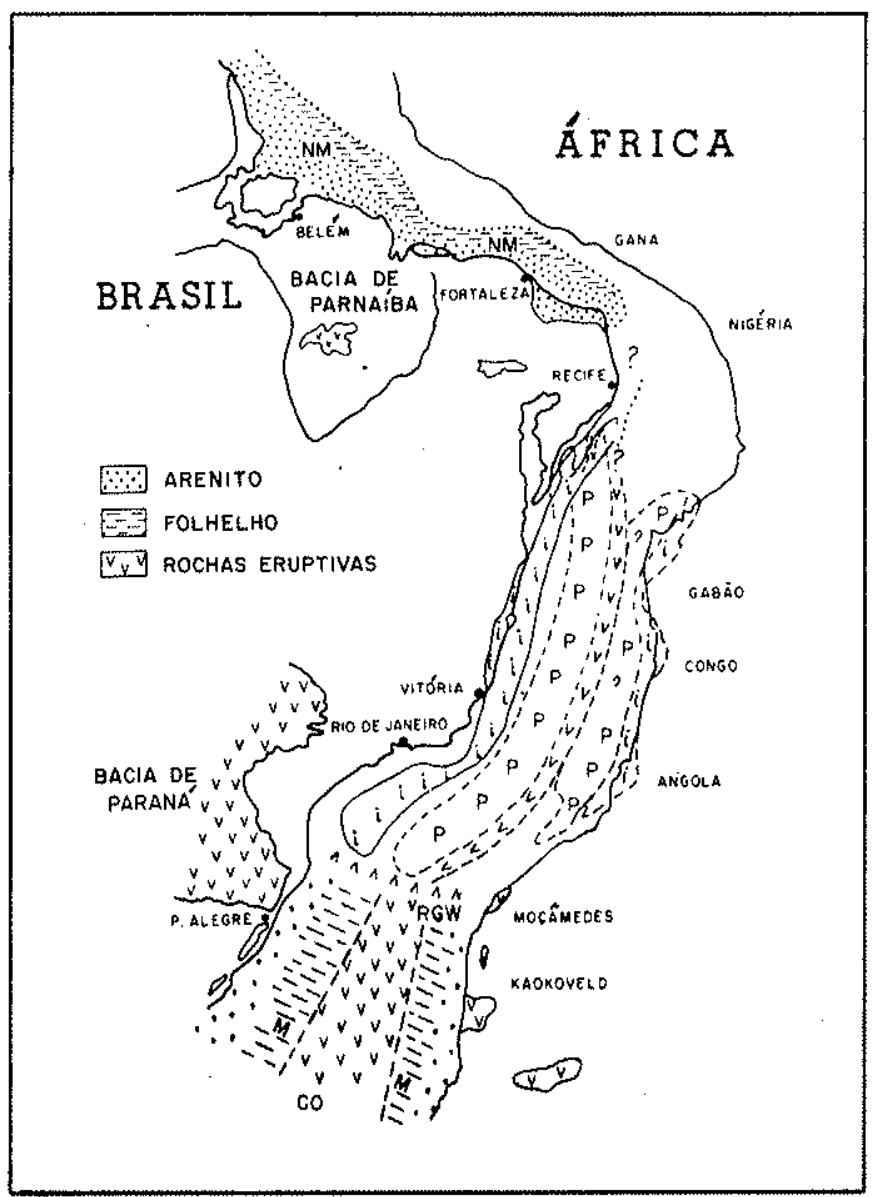

Figura 14 - Esboço paleogeografico no final do Neo-aptiano (Neo-Alagoas). Deposiçao clástica flúvio-deltaica na margem equatorial e evaporitos na margem leste brasileira, ao norte do alinhamento Rio Grande-Walvis (RGW); deposiça marinha e crescimento de crosta oceanica (CO), ao swl; $\mathrm{NM}$ - ambiente ndo-marinho; $\mathrm{M}$ - ambiente marinho; $e \mathrm{~B}$ - bacia evaportica lbura
Fase de migraçåo Esta fase, desenvolvida entre o Albiano e o Recente, caracteriza-se basicamente por basculamento generalizado para a bacia, com formação de charneira com grabens de compensação e conseqüente definição de extensa estrutura homoclinal e plataforma rasa (Fig. 3c). O tectonismo adiastrófico (representado por falhas de crescimento com rollover e diápiros de sal ou de folhelho) foi intenso, tendo havido também atividade ignea de regular intensidade (Fig. 11c). Baseando-se em variaçőes litoestratigráficas, foram diferenciados dois períodos evolutivos: Albiano-Cenomaniano e Turoniano-Recente (Figs. 15 e 16).

ALBIANO-CENOMANIANO Neste período, iniciou-se a migração continental com crescimento de crosta oceânica. Instalaram-se definitivamente condiçסes oceânicas abertas nas margens equatorial (calcários Jandaíra na Bacia Potiguar) e leste-brasileira, com provável conexão pela área Pernambuco-Rio Grande do Norte (Noguti e Santos, 1972; Reyment e Tait, 1972; Kennedy e Cooper, 1975; e Ojeda e Motta, 1976)(Fig. 15).

Outros eventos que ocorreram nesta época, e que merecem referência, são os seguintes: $a$ ) reativação de grabens assimétricos nas bacias de Barreirinhas e Cassiporé; b) desenvolvimento de plataforma e talude continentais;

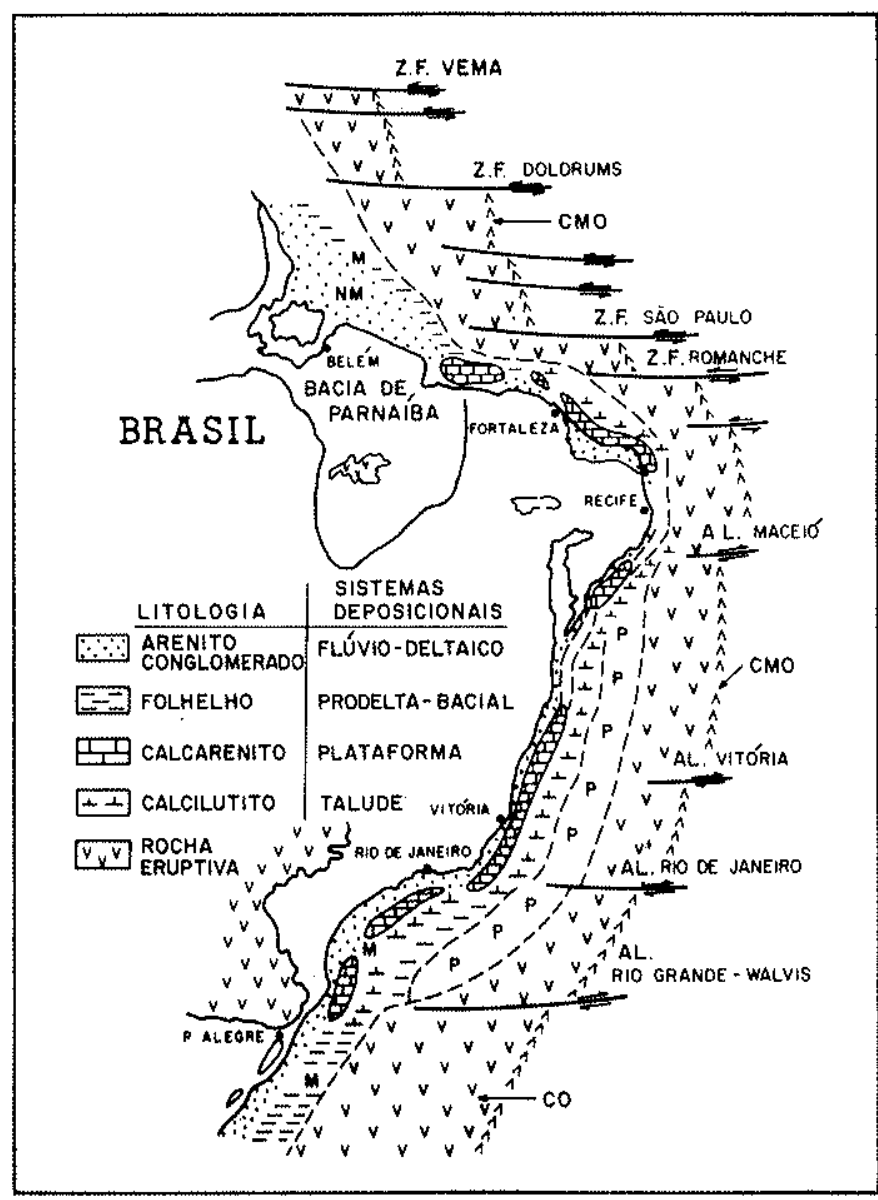

Figura 15 - Esboço paleogeográfico no final do Albiano $\mathrm{Ce}$. nomaniano. Fase de migraçdo continental, Deposiçao clásticocarbonatica dominante. RGW - Alinhamento Rio GrandeWalvis; NM - ambiente nåo-marinho; $\mathrm{M}$ - ambiente marinho; P - distribuiço dos evaporitos Paripueira (aptianos); $\mathrm{ZF}$ - zona de fratura ocednica; $\mathrm{AL}$ - alinhamento estrutural; CO - crosta oceanica; e CMO - cadela Meso-Atlantica 
c) sedimentação generalizada de seqủências clástico-carbonáticas, como calcarenitos de plataforma, calcilutitos de talude e depósitos clásticos de leques deltaicos (Figs. 7 e 8); d) deposição local de conglomerados sintectônicos associados a falhas; $e$ ) diapirismo de sal e de folhelho, especialmente intenso nas bacias da Foz do Amazonas (Miura et al., 1978), Barreirinhas (Ojeda e Motta, 1976), Bahia Sul e Santos (Ojeda e De Cesero, 1973; e Ojeda, 1977); e $f$ desenvolvimento de falhas de crescimento com rollovers associadas a deslocamento de sal ou de folhelho.

\section{TURONIANO-RECENTE Neste perfodo, os eventos} mais significativos são os seguintes: 1) migraçăo divergente das placas Sul-Americana e Africana, com crescimento de crosta oceânica; 2) continuação do desenvolvü. mento da estrutura homoclinal, com definição completa de plataforma rasa e bacia profunda; 3 ) formação de taIude e plataforma continentais, mais novos e progradados para a bacia; 4) acumulaçăo de espessa cunha sedimentar por meio de dois megaciclos deposicionais (transgressivo regressivo): o inferior, predominantemente carbonático, de plataforma e talude; e o superior, clástico. carbonático, representando depósitos de talude superior, plataforma e leques deltaicos (Figs. 9 e 16). Outrossim, na Bacia da Foz do Amazonas registra-se espessa seção terciária de sedimentos flúvio-deltaico-marinhos (Rezende e Ferradaes, 1971; e Miura et al., 1978); e 5) continuação do diapirismo de sal e de folhelho; e 6) alguma atividade ígnea.

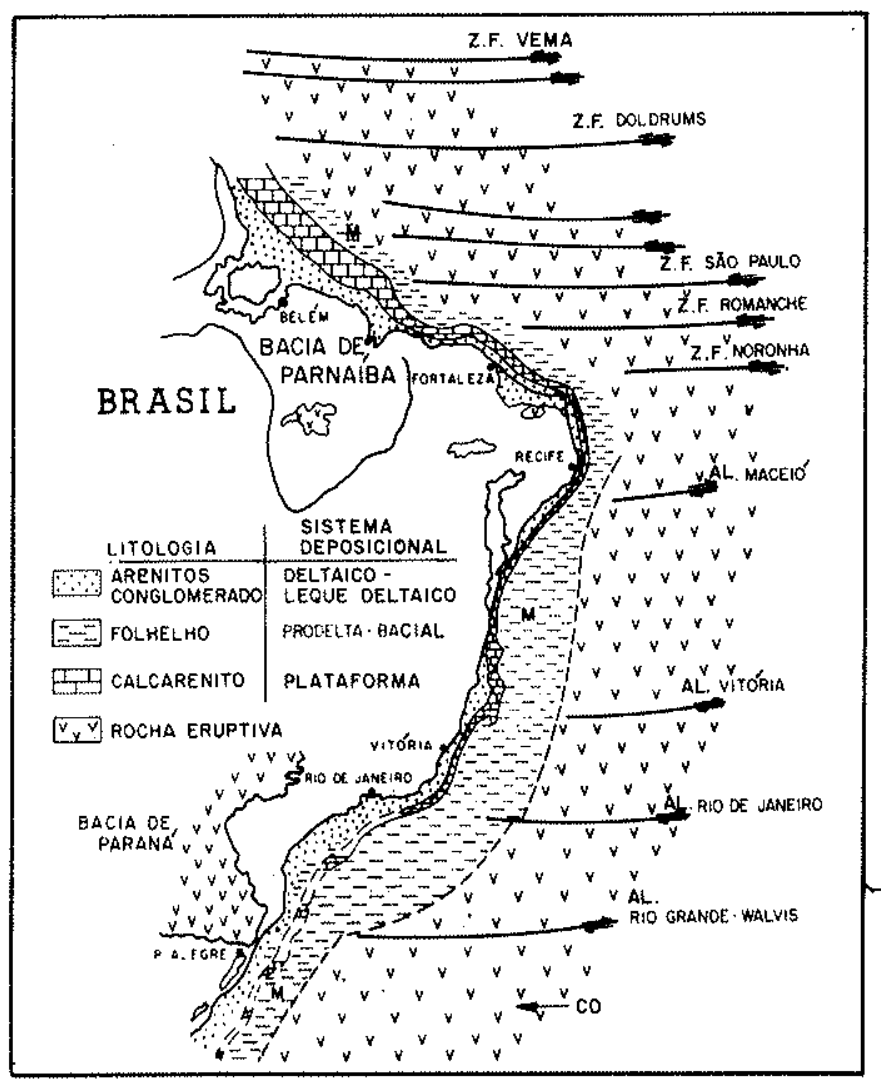

Figura 16 - Esboço paleogeografico no final do Mioceno. Fase de migraçao continental, com crescimento de crosta oceanica e deposiçao clástico-carbonática. $\mathrm{M}$ - ambiente marinho; $\mathrm{ZF}-$ zona de fratura oceanica; $\mathrm{AL}$ - alinhamento estrutural; e $\mathrm{CO}$ - crosta oceánica
POTENCIAL PETROLÍfERO O potencial petrolífero das bacias marginais brasileiras será sucintamente discutido, baseando-se principalmente no arcabouço estrutural-estratigráfico delineado ao longo deste trabalho. Destacam-se as relaçð̃es espaciais e temporais entre as estruturas, o reservatório, o selamento, as rochas geradoras $\mathrm{e}$ as acumulaçð̋es de óleo autóctone.

A produção comercial de hidrocarbonetos nessas bacias é proveniente dos seguintes reservatórios: 1) arenitos flúvio-deltaico-lacustrinos das sequências da fase rift valley (Ghignone e Andrade, 1980); 2) conglomerados policompostos de leques deltaicos sotopostos aos evaporitos Ibura (Meister e Aurich, 1972); e 3) calcarenitos e arenitos turbidíticos da sequiência oceânica neocretácea-terciária (Ojeda e Fugita, 1974; Falkenhein et al., 1977; Ponte et al., 1978; Tessari et al., 1978; e Araújo et al., 1978).

Na seqüência lacustrina da fase rift, as rochas geradoras são, mais seguramente, os clásticos mais finos de prodelta e baciais. $O$ petróleo gerado provavelmente tenha migrado através de falhas contemporâneas e se acumulou em trapas estruturais menos profundas ou adjacentes, geralmente associadas a altos intrabaciais, altos locais (situados sobre peleoaltos regionais) e rollovers (nos blocos rebaixados das falhas de crescimento). Deve-se destacar, porém, que quase todas as estruturas produtoras de petróleo na margem continental brasileira encontram-se mais ou menos relacionadás com o sistema de blocos fa lhados escalonados com basculamento sintético. Ao contrário, no sistema de blocos com basculamento antitético só pequenas acumulações têm sido encontradas até o momento.

Os evaporitos Ibura, seus equivalentes e a sequiência de conglomerados policompostos (intercalados com folhelhos) sotopostos constituem um excelente sistema petrolifero, portador de grandes quantidades de hidrocarbonetos. $O$ petróleo, quase certamente, gerado na sequência evaporítica e/ou folhelhos associados, teria migrado para os reservatórios sotopostos e, através deles, alcançado as trapas paleoestruturais, tais como os campos de Carmópolis, Riachuelo, Treme e Camorim na Ba cia de Sergipe-Alagoas (Ojeda e Fugita, 1974). Um ponto importante a ser destacado é que os ambientes evaporiticos resultantes da transgressão Ibura, que cobriram extensas áreas previamente erodidas (cobertas por depósitos de leques deltaicos), criaram condiçoes ideais para geração e trapeamento de hidrocarbonetos. Os evaporitos Paripueira, entretanto, são carentes de acumulações petrolíferas, provavelmente devido à falta de intervalos geradores e/ou distribuiçzo espacial inadequada de rochas reservatório e geradoras.

Calcarenitos, calcilutitos e arenitos turbidíticos contêm grandes quantidades de hidrocarbonetos em algumas bacias marginais brasileiras, principalmente na Bacia de Campos. As acumulações acham-se basicamente em trapas estruturais e trapas combinadas, associadas, na maioria dos casos, a rollovers das falhas de crescimento ou das estruturas de colapso; por sua vez relacionados com a movimentação de sal e/ou de folhelho.

Tendo-se em conta as consideraçðes discutidas acima, o arcabouço estrutural-estratigráfico (tal como focalizado neste trabalho) poderá ser utilizado como guia regio- 
nal na exploração petrolífera. Programações gerais e prospectos locais poderão ser enquadrados dentro de algum dos sistemas tectônicos apresentados, e avaliados, em parte, seu potencial e suas perspectivas exploratórias.

\section{DISCUSSÃO E CONCLUSÕES Baseando-se nas te-} ses discutidas neste trabalho, quatro pontos podem ser destacados como bastante originais e um tanto diferentes dos conceitos correntes:

a) Caracterização de um eixo ou zona de inversão estrutural separando dois sistemas de blocos falhados com basculamento sintético e antitético adjacentes, complementares e síncronos, desenvolvidos principalmente no Eocretáceo.

b) Caracterização e distribuição especulativa de um graben central simétrico e alongado (situado ao longo do eixo de intumescência) e de um sistema de grabens assimétricos (associados aos sistemas de blocos falhados referidos no item $a$ ). Este último sistema foi desenvolvido sobre bacias periféricas, em uma área alongada situada entre a área estável do craton e o graben central e separada deste por um alto externo.

c) Caracterização e distribuição regional de dois ciclos evaporíticos: Ibura e Paripueira.

d) Esboço do modelo geológico para a deposição das seqüências evaporíticas, utilizando-se um sistema (duplo) constituído de suprimento de água marinha (proveniente do golfo instalado ao longo do graben central) para as bacias evaporíticas, marginais, restritas, através de passagens que cortavam a barreira de restrição constituída pelo alto externo.

Outros assuntos abordados e discutidos no presente estudo podem ser resumidos da seguinte maneira:

1) Os sistemas de blocos falhados escalonados com basculamento sintético e antitético são sistemas tectônicos desenvolvidos sincronamente, na fase de fraturamento do continente Gondwana, no Eocretáceo (Neocomiano-Barremiano, estendendo-se às vezes até o Aptiano).

2) Os blocos falhados escalonados com basculamento sintético constituem um sistema tectônico negativo (gradualmente mais ativo para a bacia), com blocos menos subsidentes formando horsts intrabaciais de extensão regional. Os blocos falhados escalonados com basculamento antitético representam geneticamente um sistema as- cendente-descendente, com as porçð̃es mais elevadas dos blocos constituindo paleoestruturas.

3) O sistema de blocos falhados escalonados com basculamento antitético (distal) encontra-se mais próximo do limite crosta continental-oceânica que o sistema com basculamento sintético (proximal), e afeta, de preferência, sedimentos prodeltaicos e baciais.

4) A charneira com grabens de compensação, a plataforma rasa e a estrutura homoclinal desenvolveram-se na fase de ruptura definitiva e migraçåo divergente das placas Africana e Sul-Americana, entre o Albiano e o Recente. Nesta época, formaram-se também estruturas adiastróficas (falhas de crescimento com rollovers e feiçðes diapíricas) devido à movimentação de sal e de folhelho.

5) Sobre a estrutura homoclinal, depositou-se espessa cunha de sedimentos clásticos e carbonáticos, marinhos e não marinhos, correspondentes a depósitos de leques deltaicos, de plataforma e de talude.

6) Diápiros de sal ocorrem normalmente além do limite externo da seqüência carbonática albiano-cenomaniana. Os alinhamentos diapíricos dos evaporitos Ibura ocorrem mais próximos da costa atual (afetando sedimentos cretáceos) que os diápiros Paripueira (inferidos) que afetariam estratos cenozóicos.

7) Há dois ciclos evaporíticos (Paripueira e Ibura) separados por espessa seção clástica. Distribuem-se em franjas adjacentes ao longo da margem continental lestebrasileira, exceto na Bacià de Sergipe-Alagoas onde se encontram superpostos.

8) Os evaporitos Paripueira foram depositados em bacias evaporíticas instaladas. sobre feições tafrogênicas ainda ativas durante o Eoaptiano.

9) Os evaporitos Ibura foram depositados, em uma subseqüente fase transgressiva, em bacias instaladas em áreas antes erodidas (na "época" Paripueira) e previamente recobertas por camadas de conglomerados. Criouse assim um sistema petrolifero ideal, com a rocha geradora-selante sobreposta à rocha-reservatório.

Agradecimentos $\mathrm{O}$ autor agradece à Petrobrás pela permissão para publicar este trabalho, e aos doutores C.W.M. Campos, K. Jinno, H. Muhlmann, F.U.F. Falkenhein e M. Figueiredo pelas discussóes técnicas e revisăo do manuscrito.

\section{BIBLIOGRAFIA}

ALMEIDA, F,F,M. - 1976 - Origem e evoluç九̆o da plataforma brasileira. Bol. DNPM-DGM, 241: 1-36. Rio de Janeiro.

ARAUJO, M.B., SOUZA, S.M. e GOMES; J.B. - 1978 - The Potiguar Basin - General aspects and petroliferous prospects. Anais Offshore Brasil, 78: 02.5-02-11. Rio de Janeiro.

ASMUS, H.E. e PONTE, F.C. - 1973 - The Brasilian marginal basins: The Ocean basins and margins. Vol. 1 - The South Atlantic (Nairn and Stehli eds.). Plenum Press. New York, pp. 87-133.

ASMUS, H.E. e PORTO, R, - 1972 - Classificação das bacias sedimentares brasileiras segundo a tectónica de placas. Anais XXVI Congr. Bras. Geol. da S.B.G., Vol. 2; 67-90. Belém.

ASMUS, H.E. e CARVALHO, J.C. - 1977 - Condicionamento tectónico da sedimentaça nasibacias marginais do nordeste brasileiro (Sergipe-Alagoas e Pernambuco - Parafba). Rel. Petrobrás/Cenpes/Depro/Remac, n. 4: 8-23. Rio de Janeiro.

ASMUS, H.E. - 1977 - Hipóteses sobre a origem dos sistemas de zonas de fratura oceânicas/alinhamentos continentais que ocorrem nas regioes sudeste e sul do Brasil. Rel. Petrobrás/Cenpes/Depro/Remac, n: 4: 39-73. Rio de Janeiro.
ASMUS, H.E. - 1979 - Conocimiento actual del margen continental brasilefto. 4\% Congr. Latinoamericano de Geologla, Puerto Espana, Trinidad-Tobago. (manuscrito)

BACCAR, M.A. - 1970 - Evidencias geofisicas do pacote sedimentar no Plateau de Săo Paulo. Anais do XXIY Congr. Bras. Geol., da S.B.G., pg. 201-210.

BACOCCOLI, G., MORALES, R.G. e CASTRO, P.J.M. - 1979 - Oil exploration in the Campos basin, Brasil. A model for exploration in the Atlantic-type basins. Congr. Anual da A.A.P.G./S.E.P.M. Houston.

BARRETO, H.T. e MILLIMAN, J,D. - 1969 - Esboço fisiográfico da margem continental brasileira. Margem Continental Brasileira, L.C. Toffolli, ed. Rel. Int. Petrobrás, Vol. 1: 11-30. Rio de Janeiro.

BOYER, P.R. -1969 - Structure of the Continental Margin of Brazil, Natal to Rio de Janeiro. Ph.D. thesis, Urbana University, Hllinois, pp. 1-93.

BROWN, Jr., L.F., BAUMGARTEN, C.S., BRAGA, J.A.E. E FISHER, W.L. - 1974 - Depositional systems and petroleum potential, Foz do Amazonas area. Rel. Int. Petrobrás/Dexpro/Divex, pp. 54, Rio de Janeiro.

BROWN, Jr., L.F., DAUZACKER, M.V., SAITO, M. e FISHER, W.L. -1975 - Depositional systems and petroleum potential Santos Basin. Rel. Int. Petrobrás/Dexpro/Divex. Rio de Janeiro. 
BROWN, Jr., L.F., FUGITA, A.M. e TSUBONE, K. - 1976 - Depositiona systems and petroleum potential in the Barreirinhas basin, northern Brazil. Rel. Int. Petrobrás/Dexpro/Divex, n? 5250. Rio de Janeiro.

BRYAN, G.M., KUMAR, M. e CASTRO. P.J.M. - 1972 - The North Brazilian Ridge and the extension of equatorial fracture zones into the continents. Anais XXVI Congr. Bras. Geol. da S.B.G., Vol. 2: 133-134. Belem.

BUTLER, L.W. - $1969-$ Shallow structure of the continental margin southern Brazil and Uruguay. Bol. G.S.A., Vol. 82: 1079-1096.

CAMPOS, C.W.M., PONTE, F.C. E MIURA, K. - 1974 - Geology of the Brazilian continental margin. The Geology of Continental Margins, C.A. Bark C.L. Drake, eds., pp. 447-461. Springer-Verlag, New York.

DAUZACKER, M.V. e ANDRADE, M.A. - 1977 - Bacias Mucuri-Cumuruxatiba: Prospectos exploratórios. Rel. Int. Petrobrás/Dexpro/Divex. Rio de Janeiro.

DELTEIL, J.R., RIVIER, F., MONTADERT, L., APOSTOLESW, V., DIDIER, J., GOSLIN, M. e PATRIAT, Ph, - 1976 - Structure and sedimentation of the continental margin of the Gulf of Benin. Anais da Acad. Bras. Cienc., n? 48 (suplemento): 51-65.

DIETZ, R.S. e HOLDEN, J.C. - 1970 - The Breakup of Pangea. Continents Adrift. W.H. Freeman and Company, pp. 102-113. San Francisco.

DINGLE, R.V. - 1976 - A review of the sedimentary history of some post-permian continental margins of Atlantic-type. Anais Acad. Bras. Cienc., n? 48 (suplemento): 67-80. Săo Paulo.

ESTRELLA, G.O. - 1972 - O estágio 'rift' nas bacias marginais do leste brasileiro. Anais XXVI Congr. Bras. Geol. da S.B.G., Vol. 3: 29-34. Belém.

EVANS, R. - 1978 - Origin and significance of evaporites around Atiantic mar gin. Bol. A.A.P.G. 62, 2: 223-234

FALKENHEIN, F.U.H., ARAÚJO, M.B., SOUZA, S.M., GOMES, J.B. SOUZA, M.M. - 1977 - Relatório geológico, de progresso, da Bacia Potiguar, Rel. Int. Petrobrás/Dexpro/Divex, n: 2785 .

FISHER, W.L., OJEDA, H.A.O. e GAMA, Jr., E. - 1973 - Estratigrafia sismica e sistemas deposicionais da Formaça Piaçabuçu. Anais XXVI Congr. Bras. Geol. da S.B.G., Vol. 3: 123-134. Aracaju.

FISHER, W.L., MORALES, R.G., DELI.A PIAZZA, H. e BROWN, Jr., L.F. - 1974 - Sistemas deposicionais das bacias de Mucuri, Cumuruxatiba e Je quitinhonha. Anais XXVIII Congr. Bras. Geol, da S.B.G., Vol. 1: 13-26. Porto Alegre.

FISHER, W.L., ESTRELLA, G.O. c GOMES, J.B. - 1975 - Sistema deposi cional das formaçóes do Santoniano e Mioceno da Bacia Potiguar e suas relaçôes com exploraçấo de óleo e gás. Rel. Int. Petrobrás/Dexpro/Divex. Rio de Janeiro.

FONSECA, N.J.C. - 1973 - Evaporitos de Sergipe. Anais XXVII Congr. Bras. Geol. da S.B.G., Vol. 2: 177-246. Aracaju.

FUGITA, A.M. - 1974 - A geomorfologia da superfície de discordancia Pré-aptiana na Bacia de Sergjpe e sua relação com os campos de óleo. Anai XXVIIl Congr. Bras. Geol. da S.B.G., Vol, 1: 121-135. Porto Alegre.

GAMA, Jr., E. - 1970 -- Modelo geológico das bacias do Recôncavo e Tucano. Anais XXIV Congr. Bras. Geol. da S.B.G., pp. 191-200. Brasilia.

GHIGNONE, J.I. e ANDRADE, G. - 1970 - General geology and major oil fields of the Recôncavo basin. Publ. espec. da A.A.P.G. (Memoir 14) 337-358.

GONÇALVES, A., OLIVEIRA, M.A.M. e MOTTA, S.O. - 1979 - Geologia da Bacia de Pelotas e Plataforma de Florianópolis. Bol. Téc. Petrobrás, n: 22, Vol. 3: 157-174, Rio de Janeiro.

GORINI, M.A. e BRYAN, G.M. - 1976 - The tectonic fabric of the Equatorial Atlantic and adjoining continental margins: Gulf of Guinea to northeastern Brazil. Anais Acad, Bras. Cienc, n? 48 (suplemento): 101-129. Så Paulo.

GUAZELLI, W., COSTA, M.P.A. e KOWSMANN, R.O. - 1977 - Cruzeiro Platôs marginais do nordeste brasileiro, Rel. Int. Petrobrás/Cenpes/Depro/Remac, pp. 670-708.

KENNEDY, W.J. e COOPER, M. - 1975 - Cretaceous ammoniate distribution and opening of the South Atlantic. Journal of Geol. Soc. of London, 131: 283-288.

KUMAR, N., BRIAN, G., GORINI, M. e CARVALHO, J. - 1976- Evolution of the continental margin of northern Brazil: Sediment distribution and car bon potential. Anais da Acad. Bras. Cienc., no 48 (suplemento): 131-143.

LEYDEN, R. e NUNES, J,R, - 1972 - Diapiric structures off shore southern Brazil. Anais XXVI Congr. Bras. Geol. da S.B.G., Vol. 2: 45-50. Belém.

LEYDEN, R. - 1976 - Salt distribution and crustal models for the eastern Brazilian margin. Anais Acad. Bras. Cienc., Vol. 48 (suplemento): 159-168. Săo Paulo.

MASCLE, J.R., BORNHOLD, B.D. e RENARD, V. - 1973 - Diapiric structures off Niger Delta. Bol. A.A.P.G. 57, 9: 1672-1678.

MASCLE, J.R, e RENARD, V, - 1976 - The marginal Săo Paulo Plateau, comparison with the southern Angola margin. Anais da Acad. Bras, Cienc. n: 48 (suplemento); 179.180 .

MEISTER, E.M. e AURICH, N. - 1972 - Geologic outline and oil fields of Sergipe basin, Brazil. Bol. A.A.P.G. 56, 6: 1034-1047.

MILLIMAN, D.J. - 1978 - Morphology and structure of upper margin off southern Brazil. Bol. A.A.P.G. 62, 6: 1029-1048.

MIRANDA, L.O.S. - 1970 - Geologia das bacias da plataforma continental sul-brasileira. Anais XXIV Congr. Bras. Geol. da S.B.G., Vol. 1, pp. 129-140. Brasilia.

MIURA, K. e BARBOSA, J.C. - 1972 - Geologia da plataforma continental do Maranţåo, Piatui, Ceará e Rio Grande do Norte. Anais XXVI Congr. Bras. Geol. da S.B.G., Vol. 2: 57-66. Belém.
MIURA, K., CASTRO, J.C. e BRAGA, J.A.E. - $1978-$ Stratigraphy and structural framework of the Foz do Amazonas basin. In: Offshore Technology Conference. Houston.

MORGAN, W.V. - 1971 - Convection plumes in the lower mantle. Em: Nature vol. $230 ;$ pg. $42-43$.

NOGUTI, I. e SANTOS, J.F. dos - $1972-$ Zoneamento preliminar por foraminiferos planctônicos do Aptiano ao Mioceno na plataforma continental do Brasil. Bol. Tec. Petrobrás 15, 3: 265-283, Rio de Janeiro.

OJEDA, H.A.O. e BISOL, D.L. - 1971 - Integraçăo geológica regional da extensão submarina da bacia sedimentar de Sergipe/Alagoas. Anais XXV Congr. Bras. Geol. da S.B.G., Vol. 3: 215-225, Săo Paulo.

O.JEDA, H.A.O. - 1973 - Bacia de Santos e Pelotas: Geologia e perspectivas petroliferas: Rel. Int. Petrobrás/Sepes/Diven (Curso CAGEP I). Rio de Janeiro.

OJEDA, H.A.O., FISHER, W.L. e GAMA, Jr. E. - 1973 - Depositional systems of the Espirito Santo Group and Urucutuca Formation in the Espirito Santo basin: A preliminary report on genetic facies and petroleum potential. Rel. Int. Petrobrás/Dexpro/Divex, n: 4427. Rio de Janeiro.

OJEDA, H.A.O e DE CESERO, P. - 1973 - Bacia de Santos e Pelotas: Geologia e perspectivas petroliferas. Rel. Int. Petrobrás/Sepes/Diven, Vol. 2: 1-34 (Curso GAGEP 1). Rio de Janeiro.

OJEDA, H.A.O. e FUGITA, A.M. - 1974 - Bacia de Sergipe/Alagoas: Geolo gia regional e perspectivas petroliferas. Anais XXVIII Congr. Bras. Geol. da S.B.G., Vol. 1: 136-158. Porto Alegre.

OJEDA, H.A.O. e MOTTA, S. - 1976 - Bacias de Barreirinhas, Piauí e Ceará Geologia regional e perspectivas petroliferas. Rel. Int. Petrobrás/Dexpro/Divex, nó 5086. Rio de Janeiro.

OJEDA, H.A.O. e SILVA, A.B, - 1975 - Bacias de Santos e Pelotas: Relatório de progresso. Rel. Int. Petrobrás/Dexpro/Divex, no 4974. Rio de Janeiro.

OJEDA, H.A.O - 1976 - Bacias Pernambuco-Paraiba-Rio Grande do Norte (Maragogi-Touros): Integração geologica regional, perspectivas petroliferas e programa exploratório. Rel. Int. Petrobrás/Dexpro/Divex, n? 5240. Rio de Janeiro.

OJEDA, H.A.O. - 1977 - Bacia do Espírito Santo: Integraçăo geológica regional (Relatório de progresso). Relatório Int. Petrobrás/Dexpro/Divex, n? 5193. Rio de Janeiro.

OJEDA, H.A.O., RODRIGUES, Jr., B., BARRETO, L., MONTE, A.S., FRO TA, G. e LIMA, R.T. - 1979 - Depósito de enxofre de Castanhal: Geologia, mineralização e perspectivas de lavra (Relatório de progresso). Rel. Int Petrobrás Mineraçáo/Gerex, n? 37. Rio de Janeiro.

OJEDA; H.A.O., MURICY, A., LUCCHESI, C.F, e FUGITA, A.M - 1981 Structural framework of the onshore mesozoic brazilian marginal basins. Rel. Int. Petrobrás/Depex/Divib. Rio de Janeiro.

PONTE, F.C. - 1971 - Análise comparativa da paleogeologia dos litorais atlânticos brasileiro e africano. Rel. Int. Petrobrás/Setub/BA. Salvador.

PONTE, F.C. e ASMUS, H.E. - 1976 - The Brazilian marginal basin: curren state of knowledge. Acad. Bras. Cienc., n: 48 (suplemento): 215-240. São Paulo, Brasil.

PONTE, F.C. e ASMUS, H.E, - 1978 - Geological framework of the Brazilian continental margin. Geologishe Rundschau. 67, 1: 201-235. Stuttgart.

PONTE, F.C., DAUZACKER, M.V. e PORTO, R. 1978 - Origem e acumulaçâo de petróleo nas bacias sedimentares brasileiras. Congr. Bras. Petr., Vol. 1: 121-147. Rio de Janeiro.

REGALI, M., SANTOS, A. e UESUGUI, N, - 1974 - Palinologia dos sedimentos meso-cenozóicos do Brasil. Bol. Tec. Petrobrás 17, 4; 263-301.

REYMENT, R.A. E TAIT, E.A. - 1972 - Biostratigraphical dating of the early history of the South Atlantic Ocean. Philos. Trans. Roy. Soc, London, B., Bol. 264, pp. 55-95.

REZENDE, W.M. - 1970 - Integração geológica regional da bacia sedimentar da Foz do Amazonas. Anais XXV Congr. Bras. Geol, da S.B.G., Vol. 3, pp. 203-214. Săo Paulo.

REZENDE, W.M. e FERRADAES, J.O. - 1971 - Integração geologica regional da bacia sedimentar da Foz do Amazonas. Anais do XXV Congr. Bras. Geol. da S.B.G., Vol. 3, pp. 203-214, Sao Paulo.

RONA, P.A. - 1976 - Salt deposits of the Atlantic. Anais da Acad. Bras. Cienc., n? 48 (suplemento): 265-274.

SCHALLER, H. - 1969 - Revisão estratigráfica da Bacia de Sergipe/Alagoas. Bol. Téc. Petrobrás 12, 1: 21,86. Rio de Janeiro.

SCHALlER, H. - 1973 - Estratigrafia da Bacia de Campos. Anais XXVII Congr. Bras. Geol. da S.B.G., Vol. 3, 247-258. Aracaju.

SOUZA, M.M. - 1972 - Reconhecimento sísmico da plataforma continental do nordeste brasileiro. Rel. Int. Petrobrás, n? 4250. Rio de Janeiro.

SZATMARI, P., CARVALHO, R.S.; SIMÖES, I.A. TIBANA, P. e LEITE D.C. - 1974 -- Evaporitos de Sergipe: Geologia e geoquímica. Rel. Int. Pe trobras/Sen-ba/Sepes, Projeto Evaporitos, Vol. 1: 1.160.

TESSARI, E., TSUBONE, K. e BRIZOLA, N. - 1978 - Petroleum bearing deposits in the Campos basin. Offshore Brazil, 78: 5-14.

WENGER, R.J. - 1973 - Le basin sedimentaire gabonais et la derive des continents. Anais XXVIII Congr. Bras. Geol. da S.B.G., Vol. 3: 13-52. Aracaju. ZEMBRUSCKI, S.G., BARRETO, H.T., PALMA, J,C. e MILLIMAN, J,D. 1972 - Estudo preliminar das provincias geomorfológicas da margem continental brasileira. Anais XXVI Congr. Bras. Geol. da S.B.G., Vol. 2: 187-210. Belém.

Recebido em 22 de dezembro de 1981 